Advanced Practice Registered Nurse (APRN) Led Unit Nursing Rounds and Bedside Nurses’ Job Satisfaction

\author{
Katherine Dale Shaw \\ Earlysville, Virginia
}

Bachelor of Science in Nursing, Virginia Commonwealth University, 1980

Master of Science in Nursing, University of Virginia, 1999

A Capstone Presented to the Graduate Faculty of the University of Virginia in Candidacy for the Degree of Doctor of Nursing Practice

\author{
School of Nursing \\ University of Virginia
}

May, 2014

Arlene Keeling, PhD, RN, FAAN, Chair

Signature of Chair

Dorothy Tullmann, PhD, RN, Member

Signature of Member

Elizabeth Epstein, PhD, RN, Member

Signature of Member 


\begin{abstract}
Purpose. To explore and describe the relationship of APRN unit-based rounds and the job satisfaction of bedside nurses and to evaluate the nurses' perceived value of these rounds.

Background. The role of the APRN on a hospital unit is a critical, yet unexamined factor on nursing retention and nurse's job satisfaction, two factors linked to patient safety, outcomes and hospital Magnet status. Little research has been conducted that evaluates the relationship that the APRN role has to the bedside nurse's job satisfaction. Unit-based nursing rounds provides teaching, coaching and mentoring, facilitating continuing professional education, the integration of evidence based practice at the bedside, and group empowerment.

Design. A descriptive, exploratory, mixed-methods project to evaluate the value of APRN led unit-based rounds.
\end{abstract}

Methods. Two open ended questionnaires were distributed to 38 nurses on an acute care inpatient unit in a Mid-Atlantic teaching hospital where APRN nursing rounds have been conducted since May 2011. Conventional content analysis was undertaken. Measurements included the practice environment scale (PES) and the job enjoyment scale (JES), collected annually by the hospital. Results. Ninety two percent of nurses reported that APRN-led rounds increased their job satisfaction. Themes included: increased knowledge and professional development, collaboration with peers, feeling valued and supported, improved quality care, and increased critical thinking. Conclusion. APRN led unit based rounds is a valuable strategy to improve the bedside nurses' job satisfaction. Key words: nursing satisfaction, bedside nurses, APRNs, nursing rounds. 


\section{Acknowledgments}

This paper is a culmination of my Doctorate of Nursing Practice. I wish to thank my professors, staff, colleagues and classmates at the University of Virginia School Of Nursing. I am especially grateful to my mentor and faculty advisor Dr. Arlene Keeling for her encouragement and guidance. In addition, I cannot thank enough Drs Elizabeth Epstein and Dorothy Tullmann for their support, flexibility and inspiration. My sincere appreciation and admiration goes to the nurses on 6 West who truly are my inspiration for this project. To Susan Prather, the nurse manager on 6 West for her constant support and enthusiasm for unit based nursing rounds. To my husband, Tom, who supported me, maintained a household, and was my strength throughout this entire program. To my family and friends who understood when they did not hear from me for weeks at a time. Thank you to each of you. 


\section{Table of Contents}

Section I

Introduction and Background $\quad 6$

$\begin{array}{ll}\text { Purpose } & 9\end{array}$

Section II

$\begin{array}{ll}\text { Literature Review } & 10\end{array}$

$\begin{array}{ll}\text { Conclusion } & 15\end{array}$

Section III

Methods 16

$\begin{array}{ll}\text { Setting } & 16\end{array}$

$\begin{array}{ll}\text { Sample } & 19\end{array}$

Data Collection 20

Protection of Human Subjects $\quad 21$

Data Analysis $\quad 21$

Section IV

Results 22

$\begin{array}{ll}\text { Discussion } & 27\end{array}$

Conclusion $\quad 30$

Section V: Manuscript for Publication 31

$\begin{array}{ll}\text { References } & 57\end{array}$

Tables

Table 1: Literature on Unit-Based Rounds 63

Table 2: Unit PES and JES Ranking 66 
Appendices

Appendix 1: Questionnaire for rounds

67

Appendix 2: Demographic Questionnaire

68

Appendix 3: PES and JES

69

Appendix 4: Author Guidelines

71

Appendix 5: IRB approval

78 
Advanced Practice Registered Nurse Led Unit Nursing Rounds and Bedside Nurses' Job Satisfaction

\section{Section 1}

\section{Introduction and Background}

The role of the Advanced Practice Registered Nurse (APRN) on a hospital unit may be a critical, yet unexamined factor on nursing retention and nurse's job satisfaction, two factors that are linked to patient safety, outcomes and hospital Magnet status. To date, little research has been conducted on the relationship of the APRN role to the bedside nurse's job satisfaction. (Lashinger, Almost, \& Tuer-Hodes, 2003; Aiken, Clarke, Sloane, Lake, \& Cheney, 2008; Weston, 2010). Most research on the topic has focused on the nurses' satisfaction with the APRN's management of patient care (McMullin, Alexander, Bourgeois, \& Goodman, 2001; Shebesta et al., 2006; Stolee, Hillier, Esbaugh, Griffiths, \& Borrie, 2006; Rideout, 2007; Williamson, Twelvertree, Thompson, Beaver, 2012). These studies demonstrated nurses' satisfaction with APRN patient management.

In addition to excellence in direct clinical practice, APRNs are expected to demonstrate the additional role competencies of "guidance and coaching, consultation, evidence based practice, leadership, collaboration and ethical decision making" (Hamric, 2013, p.76). Similar to the development of professional maturity described in Benner's theory of novice to expert (Benner, 1982), the core competencies of advanced practice evolve as the APRN moves from novice to expert clinician.

The literature contains several examples of APRN involvement in guidance and coaching of patients and families. Although this is an extremely important function, guiding and coaching of the bedside nurse are arguably equally as important. Hamric, 
Spross and Hanson (2009) recommended that studies be conducted to capture the value of the guiding/coaching role of APRNs in their interactions with bedside nurses.

APRN leadership, as described by Tracy and Hanson (2013) encompasses: clinical, professional, systems and health policy leadership. Stanley (2006) defines clinical leaders as "experts in their field, and because they are approachable and effective communicators, are empowered to act as a role model, motivating others by matching their values and beliefs about nursing and care to their practice" (p.108). Leadership includes mentoring of role modeling for all team members, particularly other APRNs and nurses. Tracy and Hanson (2013) state "the responsibility to mentor is central to all the definitions of leadership and is a key element of the APN leadership competency" (p.278). Through this leadership, the APRN motivates and empowers nurses to use new knowledge and to question the status quo to improve patient care. Through empowering and mentoring bedside nurses, APRNs may improve patient outcomes and nurse satisfaction.

The Magnet Recognition Program ${ }^{\circledR}$ recognizes hospitals that demonstrate quality patient care, excellence in nursing practice and the promotion of professional nursing practice (ANCC, 2013). Magnet status is the only international credential that is specific to nursing practice. Studies conducted on nursing factors within Magnet recognized hospitals demonstrate that higher nurse satisfaction is related to less nurse burnout and better patient outcomes (Lashinger, Almost, \& Tuer-Hodes, 2003; Aiken, Clarke, Sloane, Lake, \& Cheney, 2008; Weston, 2010; Kelly, McHugh \& Aiken, 2011). Magnet hospitals report that empowered nurses feel more control over their practice thus exhibit higher satisfaction (Lashinger et al.,2003;Aiken et al., 2008; Kelly, McHugh \& Aiken, 2011). 
Stewart, Stansfield and Tapp (2004) found that autonomy leading to empowerment is encouraged through teaching rounds, educational offerings and "a climate of inquiry in everyday practice" (p.449). Weston (2010) suggests that autonomous practice is cultivated through nursing rounds, and clinical exemplars. Through intradisciplinary discussion highlighting autonomous practice, nurses learn from each other and role model effective empowering behavior.

Educational forums are strategies to build empowerment and control over nursing practice. One approach to informal education is unit-based nursing rounds conducted by an APRN. Estabrooks et al. $(2005,2008)$ and Thompson et al. (2001) found that nurses valued information obtained from human resources such as APRNs more than journals, structured educational offerings or the internet.

Considering the current understanding of the importance of nurse satisfaction on improving patient outcomes, the findings that nurses who have a sense of autonomy and control of their own practice have higher job satisfaction, and knowledge that nurses place relatively greater importance on human sources of information, APRN conducted unit rounds is a worthy strategy to increase nursing empowerment to improve nursing satisfaction. This project explores the impact of APRN-led unit-based nursing rounds on the bedside nurses' job satisfaction and evaluate the perceived value of the APRN led rounds by bedside nurses. 


\section{Purpose of the Project}

The purpose of this project is to explore and describe the relationship of APRN unit-based nursing rounds and the job satisfaction of bedside nurses and to evaluate the nurses' perceived value of these rounds.

\section{Questions Guiding the Evaluation of the Project}

1. What is the relationship between bedside nurse's job satisfaction and unit APRN-led hallway nursing rounds?

2. How do the nurses who participate in APRN-led unit-based rounds perceive these rounds? 


\section{Section II}

\section{Review of the Literature}

A systematic review of the literature was conducted examining nursing rounds, nurse satisfaction and the effect of APRN educational interaction with bedside nurses. Studies or strategies that examined APRN-led unit-based rounds were searched using Ovid Medline, CINAHL, PubMed, Google Scholar and Cochrane. Key search terms included: teaching rounds, nursing rounds, clinical rounds, nursing, nursing satisfaction, advanced practice nurses, APN, APRN, and a combination of these terms. The search was limited to the English language and the years 2003- 2013 for Medline, with no date limit for the other databases. The initial search revealed 611 potential publications. Excluded were non-English language publications, and publications not available through library services.

A review of the abstracts yielded 13 relevant articles. An ancestry search from the references of the 13 papers resulted in the identification of 10 additional articles. Fourteen of the articles focused on implementing non-unit-based rounds and were excluded (Martuscello, 1979; Batty et al., 1983; Matheny \& Wolff, 1990; Evans, 1991; Haisfield, Leach, Montgomery, Singley, Weber, 1991; Kreichelt \& Spann, 1991; McLean, Meyer, Shafer, Schoeder, 1994; Lannon, 2005; Furlong et al, 2007; Groenewold \& Diano, 2007; Iacono, 2008; Wolak, Cairns \& Smith, 2008; Armola, Brandeburg \& Tucker, 2010; Odedra \& Hitchcock, 2012).

Publications reporting strategies or studies for unit-based nursing rounds varied in design and intent. Six publications focused primarily on unit based rounds to improve patient care activities, documentation and evaluating nursing care (Cooper 1982, Coleman 
\& Henneman, 1991, Castledine et al., 2005, Close \& Castledine, 2005b, Cantugui \& Slark ,2012; Mahanes, Quatrara \& Shaw, 2013). Another article explained a formal rounding process to improve discharge planning (Mower-Wade \& Pirrung, 2010). One study described unit-based rounds as a teaching tool for nurses to improve patient outcomes (Segal \& Mason, 1998). Only one study examined unit-based nursing rounds on nurses' satisfaction (Gardner, Wollet, Richardson \& Aitken, 2010). For the purpose of this review, only the studies and strategies addressing unit based nursing rounds will be discussed. Study specifics, including details of methods, limitations and outcomes, are summarized in Table 1(p. 61)

\section{Unit Based Rounds as a Monitoring Strategy}

Close and Castledine (2005b) and Castledine, Grainger and Close (2005) used unit nursing rounds to monitor patient care activities and meet immediate patient needs similar to the process of hourly rounding. These rounds were conducted by nurse managers to ensure that nursing standards were met. Patient comfort rounds described by Castledine et al. (2005) were held to meet the physical needs of the patient in a timely manner. The authors did not describe APRNs involvement in the process and did not evaluate the effect on nurse satisfaction.

Cantugui \& Slark (2012) conducted a descriptive study to explore the effect of rounds led by an APRN, nurse manager and charge nurse on nursing care delivered to acute stroke patients. Rounds were conducted weekly, evaluating essential nursing care and stroke outcome measures (Cantugui \& Slark 2012). During rounds potential complications were addressed, and the care plan discussed with the nurse caring for the patient. One hundred and eight patients were seen during a 28 week period. The nurse-led 
stroke rounds identified early complications: including urinary tract infections $(2.7 \%)$, depression $(27.7 \%)$, oral thrush $(11.1 \%)$, genital thrush $(2.7 \%)$, and pressure sores $(2.7 \%)$. Prior to rounds, the majority of these complications were not being addressed. The nurses also reviewed all indwelling lines and found $15 \%$ with signs of early infection. Limitations include the lack of a control group and the lack of an evaluative process.

Mower-Wade and Pirrung (2010) describe a quality improvement project using APRN-led unit-based rounds on an inpatient trauma service. The rounds were developed to facilitate timely discharge, improve patient flow and increase communication among an interdisciplinary team. Consistent daily rounding, the use of a daily checklist, and the adoption of standardized discharge instructions shortened length of stay. The authors stated that the formalized rounding improved patient, nurse and physician satisfaction. No data were presented.

\section{Unit Based Rounds as a Teaching Method}

In 1982, Cooper described nursing rounds as a teaching process involving patients and families. The rounds provided opportunities for problem solving in the moment and encouraged discussion by the nurses. Rounds were held weekly and fostered learning and professional development.

Coleman and Henneman (1991) conducted a quasi-experimental study assessing the effect of informal unit-based teaching rounds on nurse's knowledge of evidencebased practice. The authors used the rounds to emphasize documentation and care planning. Rounds were conducted in a case-study format. Patients were presented by the nurse caring for the patient with contributions from other nurses with knowledge of the 
patient. An APRN guided the rounds and provided evidenced-based information.

Evaluation of the program was done through observation, questionnaire and chart audit. The questionnaire was anonymous and according to the authors all of the staff responded positively to the questions. The authors also report that staff increasingly volunteered to present and use evidence-based information.

Segal and Mason (1998) performed a quasi-experimental study evaluating the influence of APRN-led teaching rounds on pain management on an medical surgical unit. The teaching rounds emphasized informal learning, incorporting current information into nursing care. Qualitative and quantitative analysis of the rounds were performed. A questionnaire was distributed to the participants. According to the authors, $39 \%$ of the respondents rated nursing rounds as the best teaching method and $61 \%$ rated them as good. The same questionnaire asked about strengths and weaknesses of nursing rounds. Strengths included group interaction, supportive learning, knowledge acquisition and the case method (Segal \& Mason 1998). Weaknesses were time constraints, interruptions, redundancy and also the case method (Segal \& Mason 1998). The authors stressed the benefits of nursing rounds in encouraging learning and critical thinking to improve patient care. The authors conducted a comparative analysis with the staff on the participating units revealing the importance of setting a consistent time and nurse manager support.

Gardner et al. (2010) used a multi-method pilot study to explore the impact of unit-based rounds held in a unit-based classroom. During rounds nurses presented patients they were caring for and a clinical librarian provided up-to-date relevant practice information. Patients and families were included in the rounds described. A pre and post 
test was conducted using the Nursing Worklife Satisfaction Scale (NWSS) and the Practice Environment Scale (PES). Observational data collection was done weekly and included attendance, process and outcomes. The results of the study conducted revealed no statistical differences in the pre and post scores using the NWSS and PES. The response rate for the questionnaires was good, at 73\%. Aggregation of the data prevented statistical analysis for test of significance. In the NWSS the component scores of autonomy, professional status and interaction did show an increase from pre to post test (ranged from 3.29-6.69) (Gardner et al. 2010). The components of pay, task requirements and organizational policy revealed a decrease (ranged from 2.36-7.79). The results of the PES mean scores of hospital affairs, foundations for quality care and staffing and resource adequacy increased. There were no differences in manager ability, leadership or support of nurses or in $\mathrm{MD} / \mathrm{RN}$ relations. Observational data revealed that rounds were well attended. The authors reported that as nurses became more comfortable with the practice of rounding the discussions became "robust, informed by available literature and included perspectives from patients, nurses and clinical leaders" (Gardner et al.2010, p.739). Patients and families also found the rounds helpful. Limitations include the oneunit sample size and the lack of an APRN round leader.

Mahanes et al.(2013), described APRN-led unit based nursing rounds to improve nurse sensitive patient outcomes such as catheter associated urinary tract infections (CAUTI), ventilator associated pneumonia (VAP), central line-associated blood stream infections (CLABSI), falls and pressure ulcers. These rounds were held on 4 inpatient units by 3 APRNs. Nursing rounds were individualized on each unit to meet the needs of the unit culture and learning needs of the staff. Mahanes et al. (2013) concluded that 
while APRN rounds cannot be directly correlated to outcomes, positive trends in CAUTI, CLABSI, falls and pressure ulcers were noted on the units. The authors did not assess the impact of APRN-led rounds on the bedside nurses' satisfaction.

\section{Conclusion}

There are limited data on unit based APRN led nursing rounds. There are only three studies that evaluated unit based teaching rounds. Two of the studies (Colemen \& Henneman, 1991; Segal \& Mason, 1998) were done in the 1990s, with the most current study conducted by Garner et al. in 2010. All three of these studies used observational data to assess feasibility and acceptance. Two studies used open ended questionnaires to assess nursing satisfaction with the unit based nursing rounds. Only one study assessed the relationship between overall nursing satisfaction and unit based nursing rounds, and in that study rounds were not led by an APRN. There are no studies published to date that specifically examine the relationship between APRN led nursing rounds and the bedside nurses' job satisfaction. 


\section{Section III}

\section{Methods}

The purpose of this descriptive project evaluation was to explore and describe the relationship of APRN-led unit-based nursing rounds and the job satisfaction of bedside nurses and to evaluate the nurses' perceived value of these rounds.

\section{Research Design}

This was a descriptive, exploratory, mixed-methods project evaluation.

\section{Definition of terms}

For the purpose of this project the following terms are defined:

Unit based nursing rounds: an informal teaching meeting conducted on one individual acute care neurosurgical and otolaryngology unit led by an APRN. The rounds are open to all nurses, patient care technicians (PCTs), patient care assistants (PCAs), physicians and other health care team members on the unit. They are purposefully held standing in the hallway to facilitate care providers ability to go and come freely, enabling them to be available to patients and family needs.

APRN: advanced practice registered nurse. The rounds in this project are conducted by an acute care nurse practitioner (the project evaluator) who has completed all course requirements for a DNP degree.

Bedside nurse: a registered nurse who is a direct care provider on the patient care unit. The nurses on the unit have associates, baccalaureate or master's degree in nursing.

\section{Setting}

The setting for this project was one acute care inpatient unit in a Mid-Atlantic tertiary, level 1, academic medical center. The unit contains neurosurgical, 
otolaryngology and head trauma patients. It has twenty-eight beds, six of which are intermediate care. APRN nursing rounds were implemented on this unit in May 2011. The nurses on the unit have associates, baccalaureate or master's nursing degrees. In addition to APRN led nursing rounds, interdisciplinary rounds to discuss discharge planning occur Monday through Friday and all nurses participate. Nursing staff are invited to attend physician rounds on the unit. Attendance at physician rounds is difficult since it is a surgical unit, they occur quickly in the morning at the same time as the nursing shift change.

\section{APRN Rounds}

APRN nursing rounds are held on the acute care unit twice a week, once at 0430 to capture nurses working the night shift and also at 1330 for nurses working the day shift. The rounds are open to all nurses, PCAs, PCTs and other health care providers. The unit pharmacist attends most rounds and time permitting residents and interns attend rounds. They are purposefully held in the hallway to facilitate nurses' ability to go and come freely, enabling them to be available to patient and family needs. Since rounds are conducted in the hallway patient identifiers such as name, room number, date of birth, medical record number are not mentioned to protect patient and family privacy and confidentiality. The staff is vigilant in awareness of who is present in the hallway while rounds are taking place. Depending on the acuity of the patients on the unit, rounds usually last 30-45 minutes. The nurse manager of the unit is supportive of the APRN led unit nursing rounds and encourages staff to attend. Time permitting; the nurse manager also attends the APRN led unit rounds. The APRN initiates rounds by asking, "Who is your most vulnerable patient or which patient are you most concerned about?" The at-risk 
patient case guides the discussion to follow. The staff nurse presents a brief synopsis of the patient's history and current nursing care issues. Aspects of vulnerability (e.g. mobility, altered mental status, language barriers) are identified and discussion centers on reducing the impact of these vulnerabilities.

Usually one or two patients are presented. Limiting the number of patients presented allows for in-depth discussion and care planning. It also enables time to review laboratory and radiographic results. Radiographic studies such as head CTs and MRIs are reviewed with the nursing staff during rounds as necessary. This is usually done after the bedside nurse has discussed the patient's history and presenting signs and symptoms. The APRN also facilitates a discussion on the differential diagnoses for the patient.

Planning for follow-up occurs at the end of rounds. For example, it is decided who will contact the primary team if orders are needed, who will contact therapies, other consults and patients and families. Often the APRN can enter needed orders or contact the consults but the focus remains on the empowerment of the bedside nurse to take the lead on follow-through.

At times when the bedside nurses do not have a particular patient they wish to discuss, the APRN initiates discussion on other subjects that affect patient outcomes and nurse satisfaction. For example, reviewing nurse sensitive indicators such as falls, and catheter associated urinary tract infections on the unit. Suggestions for improvement are solicited from the nurses. Another example is when the APRN asked "what is the meaning of nursing autonomy for you" and then had the nurses discuss examples. 


\section{Sample}

A convenience sample of 38 registered nurses, part-time and full time on the acute care inpatient unit participating in the APRN-led nursing rounds underwent evaluation. Inclusion criteria included: nurses who participated in direct patient care at least $50 \%$ of their work hours and have worked on the unit greater than three months. Exclusion criteria included: float nurses, student nurses and patient care technicians, although they are welcomed to nursing rounds.

\section{Procedures}

Job satisfaction data (PES and JES) were collected retrospectively for 2013 using annual data collected by Nursing Services at the hospital. Two questionnaires were handdelivered to the nurses on the unit to capture their perceived value of unit based nursing rounds, job satisfaction and demographic data (age, years in nursing, years on that unit, clinical ladder status, and current degrees). For content validity these questionnaires were previously given to nurses on another unit that have the same APRN led nursing rounds but were not included in this project evaluation. The questionnaires were completed anonymously and the completed questionnaires were returned in an envelope left in the unit's nursing lounge. To increase response rates, information about the project and encouragement to complete the questionnaires occurred frequently during morning huddles on the unit. Huddles are done each morning to communicate and share pertinent information with the staff and "set the day into motion" (Dingley, Daughtery, Derieg \& Persing, 2008, p. 3). 


\section{Data Collection}

The annual nurses' job satisfaction survey, collected by the hospital, uses the practice environment scale (PES) and the job enjoyment scale (JES). The JES and PES are anonymous. The PES measures constructs such as MD/RN relationship, participation in hospital committees, manager support, staffing, and quality of nursing care. The PES uses a four point scale: strongly agree to strongly disagree. The JES measures the extent that people enjoy their work. The JES has seven statements and uses a six point scale from strongly agree to strongly disagree All PES subscales and the JES have cronbach's alpha coefficient ranging from .88 to .98 (Ballard, Bott \& Boyle, 2013).

In addition to the PES and JES, demographic data on the unit nursing staff were collected through a questionnaire developed by the project evaluator. The data included: (1) What is your current level on the clinical ladder? (2) How many years have you been a nurse? (3) How many years have you been on this unit? (4) What current degrees do you hold? (5) Are you currently enrolled in classes to pursue a higher degree? (6) What degree are you currently seeking? (7) What is your age?

An open-ended questionnaire developed by the investigator was also given to nurses on the unit. The questionnaire consists of six questions: (1) What do you like about nursing rounds? (2) What do you dislike about nursing rounds? (3) Do nursing rounds increase your knowledge? How? (4) Do you want nursing rounds to continue? Why or why not? (5) What suggestion do you have to improve nursing rounds? (6) Does having nursing rounds affect your job satisfaction? How? 


\section{Protection of Human Subjects}

Approval for this project was obtained by the University Institutional Review Board for Health Sciences Research (IRB-HSR \#17076). Every effort has been made to protect the identity of the nurses on the unit. The PES and JES conducted annually at the hospital are anonymous. The only identifying data point on one of the questionnaires was the one asking which position on the clinical ladder the respondent holds, clinician one (novice) to clinician four (expert). Consent was implied through completion of the questionnaires and participation in the annual nursing worklife job satisfaction survey.

\section{Data Analysis}

Demographic data collected from the questionnaires were entered into SPSS v. 21 and analyzed using descriptive statistics. Percentages and frequencies were calculated for categorical variables (place on career ladder, current degree). For continuous variables (age, years on unit, years as a nurse), means and standard deviations were calculated. Answers to the questionnaire measuring the nurses perceived value of APRN nursing rounds were entered verbatim into a document to facilitate conventional content analysis (Hsieh and Shannon, 2005; Ward, Furber, Tierney \& Swallow, 2013). Content analysis began with full immersion in the data followed by identification of key words. Key words were then integrated into categories. An audit trail of the process was documented so that verbatim answers could be linked to categories. To ensure credibility of the data, the key words and categories were reviewed with the original answers by an independent APRN and the investigator's faculty advisor. The PES and JES results were reviewed by the project evaluator. Individual scores were unable to be obtained from the aggregated data. This prevented statistical analysis for significance. 


\section{Section IV}

\section{Results}

\section{Sample demographics}

There was a potential sample of 38 nurses on the unit participating in APRN led nursing rounds, 25 completed both questionnaires resulting in a $66 \%$ response rate. Ten of the nurses had an associate degree in nursing, twelve had bachelor's degrees and three were masters prepared. Three nurses were a Clinician 1 (novice) on the clinical ladder, sixteen were Clinician 2 (capable clinician), three were Clinician 3 (experienced and highly skilled), one was a Clinician 4 (expert) and two were APRNs. The mean age of the nurses was 34.46 (SD 9.61) with a range of 23-57. Mean years as a nurse was 6.8 (SD 6.81) and mean years on the unit was 4.54 (SD 3.64).

\section{Practice environment scale and job enjoyment scale}

Aggregation of data from the 2013 job satisfaction survey conducted by the hospital does not allow for statistical comparison of unit level data. The unit with APRN rounds and those units without APRN rounds cannot be compared. In 2013, 57 units in the hospital completed the job satisfaction survey. The acute care unit with APRN-led nursing rounds had a $95 \%$ response rate. Table 2 reveals how the project unit (with APRN rounds) ranked in comparison to the rest of the hospital $(n=57)$. A lower number indicates a higher level of satisfaction and better practice environment. Except for collegial nurse-physician relations, the unit with the APRN-led unit rounds was in the top one-half of all hospital units. 


\section{Nurses' perceived value of Nursing Rounds and Satisfaction}

Content analysis related to nurses' perceived value of APRN rounds and their job satisfaction revealed the following themes and subthemes:

- Opportunities for learning

- Opportunities for collaboration

- Perceived improvement in quality of care

- Lack of time to engage in rounds

- Increased satisfaction

Increased competence

- Increased value as a practitioner

Nurses surveyed described APRN-led unit-based rounds as an opportunity for continued professional development and continuous learning. A typical comment was: "There is the time to learn". They enjoyed discussing their specific patients and learning new ways to care for complex patients. One nurse expressed: "learning more about the diagnosis, causes, symptoms, and our treatments for our patients". Another nurse commented, "Sometimes the unit is so busy the ability to talk about patients is difficult so this provides a great time frame to do so, and the open environment to discuss cases and concerns." Another example, one nurse stated "the chance to talk about complex patients and learn new ways of looking at how to care for your patients". A nurse described it as "being able to put together a full picture".

All of the nurses surveyed wanted to continue APRN-led unit-based rounds. One response was "I learn more- I'm new to the profession I need constant learning opportunities without judgment for not knowing". Another stated "it offers a chance to 
expand our knowledge and learn from patients even if we aren't their primary RN". Another nurse responded that "the educational benefit is huge". An experienced nurse reflected that APRN nursing rounds "provides education, be a more knowledgeable preceptor, etc." Reviewing radiological studies in rounds was important to the nurses. A nurse stated "really enjoy looking at films, something that nurses don't typically get much exposure to." Another typical response was "looking at CT/MRI images". Collaborating with peers was also viewed as a positive outcome of nursing rounds. Nurses learned from each other, "sharing your knowledge with others and learning new knowledge from others/ you give and receive". Another echoed "gives insight to other nurses' actions and thought processes on the floor". Nurses liked that the rounds were "nurse driven" and felt it increased their confidence.

Increased critical thinking and perceived improvement in the quality of care was another theme reflected in the survey results. A common response was in the statement "I feel like the knowledge I've obtained has helped me understand my patient's specific diagnosis and therefore helps me teach them more and allows me to give better care" Most nurses stated that rounds increased their competence and their ability to provide better care and that this made them satisfied with their job, For example, "It gives me valuable information to pass along to my patients or other staff and improves my practice". Another nurse shared "Especially when it is a patient I've worked with, I feel more comfortable working with them after I've been exposed to such a comprehensive review of the case, diagnosis and plan. It gives me insight into what the MDs and NPs are looking at to make determinations or diagnosis, and what they consider as differentials. I feel like I understand the whole process better". An example of increased communication 
and care described by one of the nurses was when a trauma patient with multiple comorbidities was discussed in APRN unit nursing rounds one morning. The nurse presented the patient who was scheduled for surgery that morning and was becoming increasingly more confused. His physicians were aware of his condition. The discussion centered on potential causes for his increasing confusion, which were many, and his safety. The group developed a plan to increase his monitoring, set his bed alarm to be more sensitive, for everyone to check on him frequently and arrange for potential transfer to the intermediate care unit. His nurse elaborated, "because of what we talked about, I also passed on an extra caution to the surgical admission suite (SAS) nurse about his situation and he ended up getting extremely agitated as soon as he got down there. The SAS nurse called me back to check in/report about his status and since I had been able to pass on what we talked about in rounds and a good explanation of his condition, he was actually still able to have his surgery done on time. I feel like without rounds that morning, they could easily have needed to delay surgery because I wouldn't have had the comprehensive view on his case".

A majority of nurses did not dislike nursing rounds but rather disliked that they could not attend due to time constraints and interruptions. One nurse reflected "the only thing is that sometimes is difficult to break away from patient responsibilities which is basically unavoidable." One nurse did not like that nursing rounds took place in the middle of the hallway.

Feeling valued and supported was a theme reported by the nurses that resulted in their increased satisfaction. Having time set aside to increase their knowledge and voice concerns about their patients in an environment in which they could receive immediate 
feedback from the APRN and their peers made the staff feel that their professional development was important and their role valued in patient care. One comment was "I feel supported and engaged when this is done. I really enjoy nursing rounds and learn something new every time. So, this makes me like my job more". Another nurse expressed "discussing how to improve quality of care instills a sense of importance among nurses (role of the nurse) $=$ increased satisfaction". One nurse stated "it not only allows for additional learning and experience but adds to the feeling the nursing matters on (the unit) and at (the hospital)". Another response was "lets us know someone is concerned about our knowledge and development." Nurses in the survey reported that their satisfaction was increased because APRN nursing rounds improved communication and collaboration among each other and the interdisciplinary patient care team. A refection of this was "I feel this is a positive experience that also improves our team atmosphere." Having an environment where nurses feel they are part of a team and that they are part of the larger picture also led to nurses feeling supported and valued. Their increased confidence, knowledge and feeling valued as a member of the health care team leads to empowerment of their own practice.

An example that illustrates increased communication, empowerment and quality of care is another patient presented during rounds. The patient was an elderly man who had been admitted to the hospital for altered mental status. His working diagnosis was dementia. His nurse was concerned because the changes in his mental status were fairly acute, over a two week period of time. Prior to that he had been able to manage his financial affairs, drive and was independent. On admission he was confused, had difficulty walking and was unable to be independent in activities of daily living. The 
nurse's concern was that it appeared more acute than the working diagnosis of dementia. The patient was still going through the diagnosis workup and discharge plans were leaning toward skilled nursing facility placement. The group in rounds reviewed all the potential differentials for altered mental status (e.g infection, metabolic abnormalities, trauma, medications, etc.). His radiologic studies were reviewed and it appeared on his head CT that his lateral ventricles were enlarged and he had a hyperdense lesion near his pituitary. The film had not been read by the radiologist. Discussion centered on possible diagnosis and nursing implications. At the end of rounds the nurse who presented the patient approached the primary team about the discussion during nursing rounds. The primary team consulted the neurosurgery team. The patient had a ventricular-peritoneal shunt and gamma knife treatment for his hyperdense lesion. The patient returned to his baseline and went home.

Evaluating patient outcomes was not part of this project evaluation. However there are many instances, almost weekly, in which the nursing staff specifically associated APRN-led nursing rounds to improving patient care and outcomes, such as the examples presented. Evaluating the influence of rounds on patient outcomes is an area that warrants further study.

\section{Discussion}

Few studies evaluated the effectiveness of unit-based nursing rounds on bedside nurses' job satisfaction. Only one study by Gardner et al. (2010) specifically evaluated overall nursing satisfaction with "nursing grand rounds". The investigators used the NWSS and PES as measurements for nursing job satisfaction and found no statistical differences in the pre and post implementation scores (Gardner et al., 2010). Their rounds 
were held in a classroom and not led by an APRN. The APRN rounds in this evaluation were held on the unit to enable attendance and responsiveness to patient care.

The primary goal of this evaluation was to assess whether APRN-led unit based nursing rounds impacted the bedside nurses' job satisfaction. The findings reveal that APRN-led unit-based rounds positively impact the bedside nurses' satisfaction. All but two of the nurses responding to the questionnaire stated that APRN-led nursing rounds improved their job satisfaction. The overall theme revealed that APRN-led rounds encouraged professional development and therefore increased the nurses' competence to provide better care to patients and in turn increased their satisfaction. Stewart, Stansfield and Tapp (2004) found autonomy leading to empowerment is encouraged through teaching rounds. The APRN led- rounds highlights autonomous practice, nurses learn from each other and role model effective empowering behavior. Just as important, APRN nursing rounds made nurses feel valued and supported, improved communication among their peers and the interdisciplinary team, and created a collaborative environment. According to the nurses this environment increased their job satisfaction.

The PES and JES data were reviewed for the unit with APRN led rounds. The lack of unit level data inhibits statistical comparison across units. Ranking the unit with the APRN-led unit-based rounds with the other units in the hospital revealed that except for RN/MD relations the project unit was in the top half of all hospital units (Table 2). In their study on nursing satisfaction using a similar survey tool, Gardner et al. (2010) did not find any significant differences in their pre and post intervention results. The PES and JES measurements of nursing satisfaction may not be sensitive enough to capture the impact of APRN rounds. 
An explanation for the RN/MD survey results on the project unit may be due to the fact that the unit is a surgical floor and surgeons are typically not present on the unit most of the day. Time for collaboration is limited. Since physician rounds take place at the same time as the nursing shift change it is difficult for nurses to participate in these rounds.

A second goal of this project was to evaluate whether APRN-led unit-based rounds were a valuable and worthy strategy. The results of this project support that APRN nursing rounds are a valuable tool for knowledge acquisition, development of critical thinking skills, and promotion of a team environment. When asked if they wanted to continue nursing rounds $100 \%$ of the nurses said "yes". This is also supported by previous studies assessing the effectiveness of unit teaching rounds. Coleman and Henneman (1991) evaluated their program of unit based teaching rounds through a questionnaire and found that $100 \%$ of the nurses stated they wanted more rounds and found them valuable. Gardner et al. (2010) also found nursing rounds as a viable option for professional development. Segal and Mason (1998) found that $39 \%$ of their respondents rated nursing rounds as the best teaching method and $61 \%$ rated the rounds as a good. Strengths identified in their results were similar to the findings in this project: group interaction, a supportive learning environment and that learning occurs. Two factors Segal and Mason (1998) revealed that were critical to the success of nursing rounds was a consistent time for rounds and manager support. The nursing rounds in this project were at consistent times 0430 and 1330 on specific days. Manager support cannot be emphasized enough. The nurse manager on the unit with APRN-led rounds was 
completely supportive of these rounds and encouraged staff to attend. The nurse manager also attended rounds when time permitted.

Time constraints and interruptions were seen as the biggest barriers to APRN led nursing rounds. This evidence supports the literature (Segal \& Mason, 1998). The nurses' suggestion for overcoming this obstacle is to have APRN nursing rounds more frequently. Since the APRN leading the unit-based nursing rounds maintains a busy clinical practice it may be difficult for her to increase the frequency of nursing rounds. Mentoring other APRNs in conducting unit based nursing rounds is a potential solution.

\section{Limitations}

Data relied on self reporting on the questionnaire. Only one acute care unit was surveyed and the APRN led rounds were conducted by one specific APRN. This may make generalizability difficult. Though there is a risk of bias with content analysis, having two independent reviewers should have mitigated this potential. Lastly the PES and JES results may not be the correct tools to measure nurses' satisfaction as it relates to APRN-led unit-based rounds.

\section{Conclusion}

This project has revealed new information. APRN-led unit-based nursing rounds is a valuable strategy that improves the bedside nurses' job satisfaction. Providing an open, informal environment that promotes knowledge acquisition and collegial peer relationships, nurse are empowered to have control over their own practice. This is the hallmark of Magnet institutions and is known to lead to improved patient outcomes. 


\title{
Section V
}

Manuscript for Publication; Journal of Advanced Practice

Advanced Practice Registered Nurse (APRN)-Led Unit Nursing Rounds and Bedside Nurses' Job Satisfaction

\author{
Katherine Dale SHAW, APRN, ACNP \\ Doctorate of Nursing Practice Student \\ University of Virginia \\ School of Nursing \\ Charlottesville, Virginia \\ Arlene Keeling, PhD, RN, FAAN \\ University of Virginia \\ School of Nursing \\ Charlottesville, Virginia
}

No conflict of interest has been declared by the author.

This research received no specific grant from any funding agency in the public, commercial, or not-for-profit sectors. 


\begin{abstract}
Aim. To explore and describe the relationship of APRN unit-based rounds and the job satisfaction of nurses and to evaluate the nurses' perceived value of these rounds.

Background. The role of the APRN on a hospital unit may be a critical, unexamined factor on nursing retention and job satisfaction, two factors that are linked to patient outcomes and hospital Magnet status. Little research has been conducted that evaluates the relationship the APRN role has to the bedside nurse's job satisfaction. The strategy of unit-based nursing rounds is chosen because it provides in the moment teaching, coaching and mentoring, thereby facilitating continuing professional education and also group empowerment.
\end{abstract}

Design. A descriptive, mixed-methods project to evaluate the value of APRN-led unitbased rounds in 2013.

Methods. Two open ended questionnaires were distributed to 38 nurses on an acute care inpatient unit in a United States academic hospital where APRN nursing rounds have been conducted since May 2011. Conventional content analysis was undertaken. Data measuring job satisfaction included the practice environment scale and the job enjoyment scale both collected annually by the hospital.

Results. Ninety-two percent of nurses on an acute care inpatient unit with APRN-led unit-based rounds reported that these rounds increased their job satisfaction. Themes derived from the content analysis included: increased knowledge and professional development, collaboration with peers, feeling valued and supported, perceived improved quality care, and increased critical thinking. 
Conclusion. APRN-led unit-based rounds is a valuable strategy to improve the bedside nurses' job satisfaction.

Key words: nursing satisfaction, bedside nurses, APRNs, nursing rounds. 


\section{Summary Statement}

What is already known about this topic.

- Little research has been conducted that evaluates the relationship the APRN role has to the bedside nurse's job satisfaction.

- Studies conducted on nursing factors within Magnet recognized hospitals have demonstrated that higher nurse satisfaction is related to better patient outcomes

- Nurses place greater importance on human sources of information such as APRNs rather than from sources such as journals, structured educational offerings or the internet.

What this paper adds.

- APRN-led unit rounds increases the bedside nurses' job satisfaction.

- APRN-led unit rounds are perceived by the bedside nurse as a valuable tool for knowledge acquisition, development of critical thinking skills and promotion of a team environment.

Implications for practice.

- APRN-led unit rounds is a worthy strategy to improve the bedside nurse's job satisfaction, promote professional development and potentially improve patient outcomes.

- Further research is needed to evaluate APRN-led unit rounds on patient outcomes. 


\section{Introduction and Background}

The role of the Advanced Practice Registered Nurse (APRN) on a hospital unit may be a critical, yet unexamined factor on nursing retention and job satisfaction, two factors that are linked to patient safety, outcomes and hospital Magnet status. To date, little research has been conducted on the relationship of the APRN role to nurse's job satisfaction. (Lashinger et al. 2003, Aiken et al. 2008, Weston 2010). Most research on the topic focuses on nurses' satisfaction with the APRN's management of patient care (McMullan et al. 2001, Shebesta et al. 2006, Stolee et al. 2006, Rideout 2007, Williamson et al. 2012). These studies demonstrate nurse satisfaction with APRN patient management.

In addition to excellence in direct clinical practice, APRNs are expected to demonstrate the additional role competencies of "guidance and coaching, consultation, evidence based practice, leadership, collaboration and ethical decision making" (Hamric, 2013; 76). Similar to the development of professional maturity described in Benner's theory of novice to expert (Benner 1982), the core competencies of advanced practice evolve as the APRN moves from novice to expert clinician.

The literature contains several examples of APRN involvement in guidance and coaching of patients and families. Although this is an extremely important function, guiding and coaching of nurses are arguably equally as important. Hamric et al. (2009) recommended that studies be conducted to capture the value of the guiding/coaching role of APRNs in their interactions with nurses.

APRN leadership, as described by Tracy \& Hanson, (2013) encompasses clinical, professional, systems and health policy leadership. Stanley (2006: 108) defines clinical 
leaders as "experts in their field, and because they are approachable and effective communicators, are empowered to act as a role model, motivating others by matching their values and beliefs about nursing and care to their practice". Leadership includes mentoring of and role modeling for all team members, particularly other APRNs and nurses. Tracy \& Hanson (2014: 278) state "the responsibility to mentor is central to all the definitions of leadership and is a key element of the APN leadership competency". Through this leadership, the APRN motivates and empowers nurses to use new knowledge and to question the status quo to improve patient care. Through empowering and mentoring nurses, APRNs may improve patient outcomes and nurse satisfaction.

The Magnet Recognition Program ${ }^{\circledR}$ recognizes hospitals that demonstrate quality patient care, excellence in nursing practice and the promotion of professional nursing practice (ANCC 2013). Magnet status is the only international credential that is specific to nursing practice. Studies conducted on nursing factors within Magnet recognized hospitals have demonstrated that higher nurse satisfaction is related to less nurse burnout and better patient outcomes (Lashinger et al. 2003, Aiken et al 2008, Weston 2010, Kelly et al 2011). Magnet hospitals report that empowered nurses feel more control over their practice thus exhibit higher satisfaction (Lashinger et al.2003, Aiken et al. 2008, Kelly et al. 2011). Stewart et al (2004: 449) found that autonomy leading to empowerment is encouraged through teaching rounds, educational offerings and "a climate of inquiry in everyday practice". Weston (2010) suggests autonomous practice is cultivated through nursing rounds, and clinical exemplars. Through intradisciplinary discussion, nurses learn from each other and role model empowering behavior. 
Educational forums are strategies to build empowerment and control over nursing practice. One approach to informal education is unit-based nursing rounds conducted by an APRN. Estabrooks et al. $(2005,2008)$ and Thompson et al. (2001) found that nurses valued information obtained from human resources such as APRNs more than journals, structured educational offerings or the internet. This project will explore the impact of APRN-led unit-based nursing rounds on nurse's job satisfaction and evaluate the perceived value of the APRN-led rounds by nurses. 


\section{Review of the Literature}

A systematic review of the literature was conducted examining nursing rounds, nurse satisfaction and the effect of APRN education on nurses. Studies or strategies that examined APRN-led unit-based rounds were searched using Ovid Medline, CINAHL, PubMed, Google Scholar and Cochrane. Key search terms included: teaching rounds, nursing rounds, clinical rounds, nursing, nursing satisfaction, advanced practice nurses, APN, APRN, and a combination of these terms. The search was limited to the English language and the years 2003- 2013 for Medline, with no date limit for the other databases. The initial search revealed 611 potential publications. Publications not available through library services were excluded.

A review of the abstracts yielded 13 relevant articles. An ancestry search from the references of the 13 papers resulted in the identification of 10 additional articles. Fourteen of the articles focused implementing non-unit based nursing grand rounds and were excluded (Martuscello 1979; Batty et al. 1983; Matheny \& Wolff 1990; Evans, 1991; Haisfield et al 1991; Kreichelt \& Spann 1991; McLean et al. 1994; Lannon 2005; Furlong et al. 2007; Groenewold \& Diano 2007; Iacono 2008; Wolak et al. 2008; Armola et al. 2010; Odedra \& Hitchcock 2012).

Publications reporting strategies or studies for unit-based nursing rounds varied in design and intent. Six publications focused primarily on unit based rounds to improve patient care activities, documentation and evaluating nursing care (Cooper 1982, Coleman \& Henneman 1991, Castledine et al. 2005, Close \& Castledine 2005b, Cantugui \& Slark 2012; Mahanes et al. 2013). Another article explained a formal rounding process to improve discharge planning (Mower-Wade \& Pirrung 2010). One study described unit- 
based rounds a teaching tool for nurses to improve patient outcomes (Segal \& Mason 1998). Only one study examined unit-based nursing rounds on nurses' satisfaction (Gardner et al.2010). For the purpose of this review, only the studies and strategies addressing unit based nursing rounds will be discussed. Study specifics, including details of methods, limitations and outcomes, are summarized in Table 1.

\section{Unit Based Rounds as a Monitoring Strategy}

Close \& Castledine (2005b) and Castledine et al. (2005) used nursing rounds to monitor patient care activities and meet immediate patient needs similar to the process of hourly rounding. These rounds were conducted by nurse managers to ensure that nursing care standards were met. Patient comfort rounds described by Castledine et al. (2005) were held to meet the physical needs of patients in a timely manner. The authors did not describe APRNs involvement in the process and did not evaluate the effect on nurse satisfaction.

Cantugui \& Slark (2012) conducted a descriptive study to explore the effect of rounds led by an APRN, nurse manager and charge nurse on nursing care delivered to acute stroke patients. Rounds were conducted weekly, evaluating essential nursing care and stroke outcome measures (Cantugui \& Slark 2012). During rounds potential complications were addressed and the care plan discussed with the nurse caring for the patient. One hundred and eight patients were seen during a 28 week period. The nurse-led stroke rounds identified early complications: including urinary tract infections (2.7\%), depression $(27.7 \%)$, oral thrush (11.1\%), genital thrush (2.7\%), and pressure sores (2.7\%). Prior to rounds, the majority of these complications were not being addressed. The nurses also reviewed all indwelling lines and found $15 \%$ with signs of early 
infection. Limitations include the lack of a control group and the lack of an evaluative process.

Mower-Wade and Pirrung (2010) describe a quality improvement project using APRN-led unit-based rounds on an inpatient trauma service. The rounds were developed to facilitate timely discharge, improve patient flow and increase communication among an interdisciplinary team. Consistent daily rounding, the use of a daily checklist, and the adoption of standardized discharge instructions shortened length of stay. The authors stated that the formalized rounding improved patient, nurse and physician satisfaction. No data was presented.

\section{Unit Based Rounds as a Teaching Method}

In 1982, Cooper described nursing rounds as a teaching process involving patients and families. The rounds provided opportunities for problem solving in the moment and encouraged discussion by the nurses. Rounds were held weekly and fostered learning and professional development.

Coleman and Henneman (1991) conducted a quasi-experimental study assessing the effect of informal unit-based teaching rounds on nurse's knowledge of evidencebased practice. The authors used the rounds to emphasize documentation and care planning. Rounds were conducted in a case-study format. Patients were presented by the nurse caring for the patient with contributions from other nurses with knowledge of the patient. An APRN guided the rounds and provided evidenced-based information. Evaluation of the program was done through observation, questionnaire and chart audit. The questionnaire was anonymous and according to the authors all of the staff responded 
positively to the questions. The authors also report that staff increasingly volunteered to present and use evidence-based information.

Segal and Mason (1998) performed a quasi-experimental study evaluating the influence of APRN-led teaching rounds on pain management on an medical surgical unit. The teaching rounds emphasized informal learning, incorporting current information into nursing care. Qualitative and quantitative analysis of the rounds were performed. A questionnaire was distributed to the participants According to the authors, $39 \%$ of the respondents rated nursing rounds as the best teaching method and $61 \%$ rated them as good. The same questionnaire asked about strengths and weaknesses of nursing rounds. Strengths included group interaction, supportive learning, knowledge acquisition and the case method (Segal \& Mason 1998). Weaknesses were time constraints, interruptions, redundancy and also the case method (Segal \& Mason 1998).

The authors stressed the benefits of nursing rounds in encouraging learning and critical thinking improving patient care. The authors conducted a comparative analysis on the participating units revealing the importance of setting a consistent time and nurse manager support.

Gardner et al. (2010) used a multi-method pilot study to explore the impact of unit-based rounds held in a unit-based classroom. During rounds nurses presented patients they were caring for and a clinical librarian provided up-to-date relevant practice information. Patients and families were included in the rounds described. A pre and post test was conducted using the Nursing Worklife Satisfaction Scale (NWSS) and the Practice Environment Scale (PES). 
Observational data collection was done weekly and included attendance, process and outcomes. The results of the study conducted revealed no statistical differences in the pre and post scores using the NWSS and PES. The response rate for the questionnaires was good, at $73 \%$. In the NWSS the component scores of autonomy, professional status and interaction did show an increase from pre to post test (ranged from 3.29-6.69) (Gardner et al. 2010). The components of pay, task requirements and organizational policy revealed a decrease (ranged from 2.36-7.79). The results of the PES mean scores of hospital affairs, foundations for quality care and staffing and resource adequacy increased. There were no differences in manager ability, leadership or support of nurses or in $\mathrm{MD} / \mathrm{RN}$ relations.

Observational data revealed that rounds were well attended. The author reported that as nurses became more comfortable with the practice of rounding the discussions became "robust, informed by available literature and included perspectives from patients' nurses and clinical leaders" (Gardner et al. 2010:739). Patients and families also found the rounds helpful. Limitations include the one-unit sample size and the lack of an APRN round leader.

Mahanes et al.(2013), described APRN-led unit based nursing rounds to improve nurse sensitive patient outcomes such as catheter associated urinary tract infections (CAUTI), ventilator associated pneumonia (VAP), central line-associated blood stream infections (CLABSI), falls and pressure ulcers. These rounds were held on 4 inpatient units by 3 APRN. Nursing rounds were individualized on each unit to meet the needs of the unit culture and learning needs of the staff. Mahanes et al.(2013) concluded that while APRN rounds cannot be directly correlated to outcomes, positive trends in CAUTI, 
CLABSI, falls and pressure ulcers were noted on the units. The authors did not assess the impact of APRN-led rounds on the bedside nurses' satisfaction.

\section{Gaps in the Literature}

There is limited data on unit based APRN-led nursing rounds. There are no studies published to date that specifically examine the relationship between APRN-led nursing rounds and nurses job satisfaction.

\section{Methods}

The purpose of this descriptive study was to describe the relationship of APRNled unit based nursing rounds and the job satisfaction of nurses and to evaluate the nurses' perceived value of these rounds during 2013. The investigator received Institutional Review Board approval to conduct the analysis.

\section{Setting}

The setting for this project was an acute care inpatient unit in a Mid-Atlantic, academic medical center. The unit contains neurosurgical, otolaryngology and head trauma patients. It has twenty eight beds, six of which are intermediate care. The nurses on the unit have associate, baccalaureate or masters nursing degrees. APRN (acute care nurse practitioner)-led nursing rounds were first implemented in May 2011. In addition to APRN led nursing rounds, interdisciplinary rounds to discuss discharge planning occur Monday through Friday and all nurses participate. Nursing staff are invited to attend physician rounds on the unit. Attendance at physician rounds is difficult since it is a surgical unit, they occur quickly in the morning at the same time as the nursing shift change. 


\section{APRN Rounds}

APRN nursing rounds are held on the acute care unit twice a week, once at 0430 to capture nurses working the night shift and also at 1330. The rounds are open to all nurses, patient care technicians (PCTs), patient care assistants (PCAs), physicians and other health team members on the unit. They are purposefully held in the hallway to facilitate nurses' ability to go and come freely, enabling them to be available to patient and family needs. Since rounds are conducted in the hallway patient identifiers such as name, room number, date of birth, medical record number are not mentioned to protect patient and family privacy and confidentiality. The staff is vigilant in awareness of who is present in the hallway while rounds are taking place. Depending on the acuity of the patients on the unit, rounds usually last $30-45$ minutes. The nurse manager of the unit is supportive of the APRN-led rounds and encourages staff to attend. Time permitting; the nurse manager also attends the rounds. The APRN initiates rounds by asking, "Who is your most vulnerable patient or which patient are you most concerned about?" The at-risk patient case guides the discussion to follow. The staff nurse presents a brief synopsis of the patient's history and current nursing care issues. Aspects of vulnerability (e.g. mobility, altered mental status, language barriers) are identified and discussion centers on reducing the impact of these vulnerabilities. Usually one or two patients are presented. Limiting the number of patients presented allows for in-depth discussion and care planning. It also enables time to review laboratory and radiographic results.

Radiographic studies such as head CTs and MRIs are reviewed during rounds. This is usually done after the nurse has discussed the patient's history and presenting 
signs and symptoms. The APRN also facilitates a discussion on the differential diagnoses for the patient.

Planning for follow-up also occurs at the end of rounds. For example, it is decided at that time who will contact the primary team if orders are needed, who will contact therapies, other consults and patients and families. Often the APRN can enter needed orders or contact the various consults but the focus remains on the empowerment of the bedside nurse to take the lead on follow-through.

\section{Sample}

A convenience sample of 38 registered nurses, part-time and full time on the acute care inpatient unit participating in the APRN-led rounds underwent evaluation. Inclusion criteria included: nurses who participated in direct patient care at least $50 \%$ of their work hours and who worked on the unit greater than three months. Exclusion criteria included: float nurses, student nurses and patient care technicians, although they are welcomed to nursing rounds.

\section{Procedures}

Job satisfaction data (PES and JES) was collected retrospectively for 2013 using annual data collected by Nursing Services at the hospital. The perceived value of rounds and nursing satisfaction was elicited through questionnaires. For content validity these

questionnaires were previously given to nurses on another unit that have the same APRNled nursing rounds but were not included in this project. The questionnaires were completed anonymously. 


\section{Measures}

The annual nurses' job satisfaction survey, collected by the hospital, uses the practice environment scale (PES) and the job enjoyment scale (JES). The PES measures constructs such as MD/RN relationship, participation in hospital committees, manager support, staffing, and quality of nursing care. The PES uses a four point scale: strongly agree to strongly disagree. The JES measures the extent that people enjoy their work. The JES has seven statements and uses a six point scale from strongly agree to strongly disagree All PES subscales and the JES have cronbach's alpha coefficient ranging from .88 to .98 (Ballard et al. 2013).

In addition to the PES and JES, demographic data on the unit nursing staff was collected. The data included: (1) What is your current level on the clinical ladder? (2) How many years have you been a nurse? (3) How many years have you been on this unit? (4) What current degrees do you hold? (5) Are you currently enrolled in classes to pursue a higher degree? (6) What degree are you currently seeking? (7) What is your age? The only identifying data point was the question asking about clinical ladder position. Otherwise the data was anonymous.

An open-ended questionnaire to assess perceived value of APRN-led rounds was also given to nurses on the unit. The questionnaire consists of six questions: (1) What do you like about nursing rounds? (2) What do you dislike about nursing rounds? (3) Do nursing rounds increase your knowledge? How? (4) Do you want nursing rounds to continue? Why or why not? (5) What suggestion do you have to improve nursing rounds?

(6) Does having nursing rounds affect your job satisfaction? How? 


\section{Data Analysis}

Demographic data collected from the questionnaires were entered into SPSS v. 21 and analyzed using descriptive statistics. Percentages and frequencies were calculated for categorical variables (place on career ladder, current degree). For continuous variables (age, years on unit, years as a nurse), means and standard deviations were calculated.

Answers to the questionnaire measuring the nurses' perceived value of APRN nursing rounds were entered verbatim onto a document to facilitate conventional content analysis (Hsieh \& Shannon 2005, Ward et al. 2013). Content analysis began with full immersion in the data followed by identification of key words. Key words were integrated into categories. An audit trail of the process was documented so that verbatim answers could be linked to categories. To ensure credibility of the data, the key words and categories were reviewed with the original answers by an independent APRN and the investigator' faculty advisor. The PES and JES results were reviewed by the project evaluator. Individual scores were unable to be obtained from the aggregated data. This prevented statistical analysis for significance.

\section{Results}

\section{Sample demographics}

There was a potential sample of 38 nurses on the unit participating in APRN-led nursing rounds, 25 completed both questionnaires resulting in a $66 \%$ response rate. Ten of the nurses had an associate degree in nursing, twelve had bachelor's degrees and three were masters prepared. Three nurses were a Clinician 1 (novice) on the clinical ladder, sixteen were Clinician 2 (capable clinician), three were Clinician 3 (experienced and highly skilled), one was a Clinician 4 (expert) and two were APRNs. The mean age of the 
nurses was 34.46 (SD 9.61) with a range of 23-57. Mean years as a nurse was 6.8 (SD 6.81) and mean years on the unit was 4.54 (SD 3.64).

Practice environment scale and job enjoyment scale

Aggregation of data from the 2013 job satisfaction survey conducted by the hospital does not allow for statistical comparison of unit level data. The unit with APRN rounds and those units without APRN rounds cannot be compared. In 2013, 57 units in the hospital completed the job satisfaction survey. The acute care unit with APRN-led nursing rounds had a 95\% response rate. Table 2 reveals how the project unit (with APRN rounds) ranked in comparison to the rest of the hospital ( $n=57)$. A lower number indicates a higher level of satisfaction and better practice environment. Except for collegial nurse-physician relations, the unit with the APRN unit led rounds was in the top one-half of all hospital units.

\section{Nurses' perceived value of Nursing Rounds and Satisfaction}

Content analysis related to nurses' perceived value of APRN rounds and their job satisfaction revealed the following themes and subthemes:

- Opportunities for learning

- Opportunities for collaboration

- Perceived improvement in quality of care

- Lack of time to engage in rounds

- Increased satisfaction

- Increased competence

- Increased value as a practitioner 
Nurses surveyed described APRN-led unit-based rounds as an opportunity for continued professional development and continuous learning. A typical comment was: "There is the time to learn". They enjoyed discussing their specific patients and learning new ways to care for complex patients. One nurse expressed: "learning more about the diagnosis, causes, symptoms, and our treatments for our patients". Another nurse commented, "Sometimes the unit is so busy the ability to talk about patients is difficult so this provides a great time frame to do so, and the open environment to discuss cases and concerns." Another example, one nurse stated "the chance to talk about complex patients and learn new ways of looking at how to care for your patients". A nurse described it as "being able to put together a full picture".

All of the nurses surveyed wanted to continue APRN-led unit-based rounds. One response was “I learn more- I'm new to the profession I need constant learning opportunities without judgment for not knowing". Another stated "it offers a chance to expand our knowledge and learn from patients even if we aren't their primary RN'. Another nurse responded that "the educational benefit is huge". An experienced nurse reflected that APRN nursing rounds "provides education, be a more knowledgeable preceptor, etc." Reviewing radiological studies in rounds was important to the nurses. A nurse stated "really enjoy looking at films, something that nurses don't typically get much exposure to." Another typical response was "looking at CT/MRI images".

Collaborating with peers was also viewed as a positive outcome of nursing rounds. Nurses learned from each other, "sharing your knowledge with others and learning new knowledge from others/ you give and receive". Another echoed "gives 
insight to other nurses' actions and thought processes on the floor". Nurses liked that the rounds were "nurse driven" and felt it increased their confidence.

Increased critical thinking and perceived improvement in the quality of care was another theme reflected in the survey results. A common response was in the statement "I feel like the knowledge I've obtained has helped me understand my patient's specific diagnosis and therefore helps me teach them more and allows me to give better care" Most nurses stated that rounds increased their competence and their ability to provide better care and that this made them satisfied with their job, For example, "It gives me valuable information to pass along to my patients or other staff and improves my practice". Another nurse shared "Especially when it is a patient I've worked with, I feel more comfortable working with them after I've been exposed to such a comprehensive review of the case, diagnosis and plan. It gives me insight into what the MDs and NPs are looking at to make determinations or diagnosis, and what they consider as differentials. I feel like I understand the whole process better". An example of increased communication and care described by one of the nurses was when a trauma patient with multiple comorbidities was discussed in APRN unit nursing rounds one morning. The nurse presented the patient who was scheduled for surgery that morning and was becoming increasingly more confused. His physicians were aware of his condition. The discussion centered on potential causes for his increasing confusion, which were many, and his safety. The group developed a plan to increase his monitoring, set his bed alarm to be more sensitive, for everyone to check on him frequently and arrange for potential transfer to the intermediate care unit. His nurse elaborated, "because of what we talked about, I also passed on an extra caution to the surgical admission suite (SAS) nurse about his 
situation and he ended up getting extremely agitated as soon as he got down there. The SAS nurse called me back to check in/report about his status and since I had been able to pass on what we talked about in rounds and a good explanation of his condition, he was actually still able to have his surgery done on time. I feel like without rounds that morning, they could easily have needed to delay surgery because I wouldn't have had the comprehensive view on his case".

A majority of nurses did not dislike nursing rounds but rather disliked that they could not attend due to time constraints and interruptions. One nurse reflected "the only thing is that sometimes is difficult to break away from patient responsibilities which is basically unavoidable." One nurse did not like that nursing rounds took place in the middle of the hallway.

Feeling valued and supported was a theme reported by the nurses that resulted in their increased satisfaction. Having time set aside to increase their knowledge and voice concerns about their patients in an environment in which they could receive immediate feedback from the APRN and their peers made the staff feel that their professional development was important and their role valued in patient care. One comment was "I feel supported and engaged when this is done. I really enjoy nursing rounds and learn something new every time. So, this makes me like my job more". Another nurse expressed "discussing how to improve quality of care instills a sense of importance among nurses (role of the nurse) = increased satisfaction". One nurse stated "it not only allows for additional learning and experience but adds to the feeling the nursing matters on (the unit) and at (the hospital)". Another response was "lets us know someone is concerned about our knowledge and development." Nurses in the survey reported that 
their satisfaction was increased because APRN nursing rounds improved communication and collaboration among each other and the interdisciplinary patient care team. A refection of this was "I feel this is a positive experience that also improves our team atmosphere." Having an environment where nurses feel they are part of a team and that they are part of the larger picture also led to nurses feeling supported and valued. Their increased confidence, knowledge and feeling valued as a member of the health care team leads to empowerment of their own practice.

An example that illustrates increased communication, empowerment and quality of care is another patient presented during rounds. The patient was an elderly man who had been admitted to the hospital for altered mental status. His working diagnosis was dementia. His nurse was concerned because the changes in his mental status were fairly acute, over a two week period of time. Prior to that he had been able to manage his financial affairs, drive and was independent. On admission he was confused, had difficulty walking and was unable to be independent in activities of daily living. The nurse's concern was that it appeared more acute than the working diagnosis of dementia. The patient was still going through the diagnosis workup and discharge plans were leaning toward skilled nursing facility placement. The group in rounds reviewed all the potential differentials for altered mental status (e.g infection, metabolic abnormalities, trauma, medications, etc.). His radiologic studies were reviewed and it appeared on his head CT that his lateral ventricles were enlarged and he had a hyperdense lesion near his pituitary. The film had not been read by the radiologist. Discussion centered on possible diagnosis and nursing implications. At the end of rounds the nurse who presented the patient approached the primary team about the discussion during nursing rounds. The 
primary team consulted the neurosurgery team. The patient had a ventricular-peritoneal shunt and gamma knife treatment for his hyperdense lesion. The patient returned to his baseline and went home.

Evaluating patient outcomes was not part of this project evaluation. However there are many instances, almost weekly, in which the nursing staff specifically associated APRN-led nursing rounds to improving patient care and outcomes, such as the examples presented. Evaluating the influence of rounds on patient outcomes is an area that warrants further study.

\section{Discussion}

Few studies evaluated the effectiveness of unit-based nursing rounds on nurses' job satisfaction. Only one study by Gardner et al.(2010) specifically evaluated overall nursing satisfaction with "nursing grand rounds". The investigators used the NWSS and PES as measurements for nursing job satisfaction and found no statistical differences in the pre and post implementation scores (Gardner et al. 2010). Their rounds were held in a classroom and not led by an APRN. The APRN rounds in this evaluation were held on the unit to enable attendance and responsiveness to patient care.

The primary goal of this evaluation was to assess whether APRN-led unit-based nursing rounds impacted nurses' job satisfaction. The findings reveal that APRN-led unitbased rounds positively impact nurses' satisfaction. All but two of the nurses responding to the questionnaire stated that APRN-led nursing rounds improved their job satisfaction. The overall theme revealed that APRN-led rounds encouraged professional development and therefore increased the nurses' competence to provide better care to patients and in turn increased their satisfaction. Stewart, Stansfield and Tapp (2004) found autonomy 
leading to empowerment is encouraged through teaching rounds. The APRN led rounds highlights autonomous practice, nurses learn from each other and role model effective empowering behavior. Just as important, APRN nursing rounds made nurses feel valued and supported, improved communication among their peers and the interdisciplinary team, and created a collaborative environment. According to the nurses this environment increased their job satisfaction.

The PES and JES data were reviewed for the unit with APRN-led rounds. The lack of unit level data inhibits statistical comparison across units. Ranking the unit with the APRN-led unit-based rounds with the other units in the hospital revealed that except for RN/MD relations the project unit was in the top half of all hospital units (Table 2). In their study on nursing satisfaction using a similar survey tool, Gardner et al. (2010) did not find any significant differences in their pre and post intervention results. The PES and JES measurements of nursing satisfaction may not be sensitive enough to capture the impact of APRN rounds.

A second goal of this project was to evaluate whether APRN-led unit-based rounds were a valuable and worthy strategy. The results of this project support that APRN nursing rounds are a valuable tool for knowledge acquisition, development of critical thinking skills, and promotion of a team environment. When asked if they wanted to continue nursing rounds $100 \%$ of the nurses said "yes". This is also supported by previous studies assessing the effectiveness of unit teaching rounds. Coleman \& Henneman (1991) evaluated their program of unit based teaching rounds through a questionnaire and found that $100 \%$ of the nurses stated they wanted more rounds and found them valuable. Gardner et al. (2010) also found nursing rounds as a viable option 
for professional development. Segal \& Mason (1998) found that 39\% of their respondents rated nursing rounds as the best teaching method and $61 \%$ rated the rounds good. Strengths identified in their results were similar to the findings in this project: group interaction, a supportive learning environment and that learning occurs. Two factors Segal \& Mason (1998) revealed that were critical to the success of nursing rounds were a consistent time for rounds and manager support. The nursing rounds in this project were at consistent times 0430 and 1330 on specific days. Manager support cannot be emphasized enough. The nurse manager on the unit with APRN-led rounds was completely supportive of these rounds and encouraged staff to attend. The nurse manager also attended rounds when time permitted.

Time constraints and interruptions were seen as the biggest barriers to APRN-led nursing rounds. This evidence supports the literature (Segal \& Mason 1998). The nurses' suggestion for overcoming this obstacle is to have APRN nursing rounds more frequently. Since the APRN leading the rounds maintains a busy clinical practice it may be difficult for her to increase the frequency of nursing rounds. Mentoring other APRNs in conducting unit based nursing rounds is a potential solution.

\section{Limitations}

Data relied on self reporting on the questionnaire. Only one acute care unit was surveyed and the APRN-led rounds were conducted by one specific APRN. This may make generalizability difficult. Though there is a risk of bias with content analysis, having two independent reviewers should have mitigated this potential. Lastly the PES and JES results may not be the correct tools to measure nurses' satisfaction as it relates to APRN-led unit based rounds. 


\section{Conclusion}

This project revealed new information. APRN-led unit-based nursing rounds is a valuable strategy that improves nurses' job satisfaction. Providing an open, informal environment that promotes knowledge acquisition and collegial peer relationships, nurse are empowered to have control over their own practice. This is the hallmark of Magnet institutions and is known to lead to improved patient outcomes. 


\section{References}

Aiken, L. H., Clarke, S. P., Sloane, D. M., Lake, E. T., \& Cheney, T. (2008). Effects of hospital care environment on patient mortality and nurse outcomes. Journal of Nursing Administration, 38(5), 223-229.

American Nurses Credentialing Center. (2013). Program Overview - American Nurses Credentialing Center - ANCC. Retrieved from http://www.nursecredentialing.org/Magnet/ProgramOverview.

Armola, R. R. , Brandeburg, J.,\& Tucker, D. (2010). A guide to developing nursing grand rounds. Critical Care Nurse, 30:46-55.

Ballard, N., Bott, M. J., Boyle, D. K.(2013). Using the practice environment scale and the job enjoyment scale to evaluate Laschinger's nursing worklife model. [Abstract]. $7^{\text {th }}$ Annual American Nurses Association's Nursing Quality Conference, Atlanta.

Batty, K., Cook, P. D., Kreutzer, L.,Peckous, B., Post, B., Rees, E. M. (1983). NGR: A project. Nursing Management, 14(12), 56-59.

Catangui, E. J., Slark, J. (2012). Nurse-led ward rounds: A valuable contribution to acute stroke care. British Journal of Nursing, 21(13), 801-805.

Close, A.,Castledine, G. (2005). Clinical nursing rounds part 2: Nurse management rounds. British Journal of Nursing, 14(16), 872-874.

Close, A.,Castledine, G. (2005). Clinical nursing rounds part 4: Teaching rounds for nurses. British Journal of Nursing, 14(18), 982-983.

Colemen, S., \& Henneman, E. (1991). Comprehensive patient care and documentation through unit-based nursing rounds. Clinical Nurse Specialist, 5(2), 117-120. 
Cooper, S. S. (1982). Methods of teaching revisited nursing rounds and bedside clinics. The Journal of Continuing Education in Nursing, 13(5), 19-21.

Dingley, C., Daugherty, K., Derieg, M.K., Persing, R.(2008). Improving Patient Safety Through Provider Communication Strategy Enhancements. In: Henriksen K, Battles JB, Keyes MA, et al., editors. Advances in Patient Safety: New Directions and Alternative Approaches (Vol. 3: Performance and Tools). Rockville (MD): Agency for Healthcare Research and Quality (US); 2008 Aug. Available from: http://www.ncbi.nlm.nih.gov.proxy.its.virginia.edu/books/NBK43663/

Estabrooks, C. A.,Rutakumwa, W., O'Leary, K. A.,Profetto-McGath, J., Milner, M, Levers, M. J., Scott-Findlay, S. (2005). Sources of practice knowledge among nurses. Qualitative Health Research, 15(4), 460-476.

Estabrooks, C. A., Scott, S., Squires, J. E., Stevens, B., O'Brien-Pallas, L., Watt-Watson, J., ... Williams, J. (2008). Patterns of research utilization on patient care units. Implementation Science, 3(1), 31.

Evans, B. (1991). Grand rounds for SNs and RNs. Advancing Clinical Care, 4(6), 30-1.

Furlong, K. M., D'Luna-O'Grady, L., Macari-Hinson, M., O'Connel, K. B., Perez, E. L., \& Pierson, G. S. (2007). Implementing Nursing Grand Rounds in a Community Hospital. Clinical Nurse Specialist, 21(6), 287-291.

Gardner, G., Wollett, K., Richardson, B., \& Aitken, L. (2010). Innovation in clinical learning for the acute hospital environment: Nursing grand rounds. Nurse Education Today, 30(8), 737-741.

Groenewold, L. \& Diano, R. B., (1991).Who talks to horses anyway? Emphasis Nursing, 4(1): 69-73. 
Haisfield ,M. E., Leach, K., Montgomery, L., Singley, C., Weber, C. (1991). Costeffective practice as a focus for nursing grand rounds. Oncology Nursing Forum, $18(7), 1246$.

Hamric, A. B. (2009) A Definition of Advanced Practice Nursing. In A.B. Hamric, J.A. Spross, \& C. M. Hanson (Eds.),Advanced Practice Nursing: An Integrative Approach. (pp. 75-94; $4^{\text {th }}$ ed.). St. Louis, MO: Saunders/Elsevier.

Hamric, A. B. (2013). A Definition of Advanced Practice Nursing. In A.B. Hamric, C. M. Hanson, M.F. Tracy, \& E.T. O' Grady (Eds.),Advanced Practice Nursing: An Integrative Approach. (pp. 67-85; $5^{\text {th }}$ ed.). St. Louis, MO: Saunders/Elsevier.

Hseih, H., Shannon, S.E.(2005). Three approaches to qualitative content analysis. Qualitative Health Research, 15(9), 1277-1288.

Iacono, M. V. (2008). Showcasing nursing talent: Nursing grand rounds. Journal of Perianesthesia Nursing, 23(5), 349-354.

Kelly, L. A., McHugh, M.D., Aiken, L.H. (2011).Nurse outcomes in Magnet巴 and nonmagnet hospitals. Journal of Nursing Administration, 41(10), 424-433.

Kreichelt, G., Spann, K. (2012). Brief: medical nursing grand rounds: Learning, sharing, caring. The Journal of Continuing Education in Nursing, 22(1), 35.

Lannon, S. L. (2005). Nursing grand rounds: promoting excellence in nursing. Journal for Nurses in Staff Development, 21(5), 221-226.

Lashinger, H. K., Almost, J., \& Tuer-Hodes, D. (2003). Workplace empowerment and Magnet Hospital characteristics. Journal of Nursing Administration, 33(7/8), 410422.

Martuscello, B. (1979). Nursing grand rounds. Health Care Education, 8(3), 17-18. 
Matheny, M. L.,\& Wolff, L. M.( 1990). Nursing grand rounds: Critical dimensions of chronic care. Journal of Cardiovascular Nursing, 4(3), 71-78.

McMullin, M., Alexander, M., Bourgeois, A., \& Goodman, L. (2001). Evaluating a nurse practitioner service. Dimensions of Critial Care Nursing, 20(5), 30-43.

McLean, P., Meyer, K., Schafer, B., Schroeder, B. (1994). Nursing grand rounds facilitate staff development. Oncology Nursing Forum, 21(3), 600.

Mower-Wade, D., Pirrung, J. M. (2010). Advanced practice nurses making a difference: Implementation of a formal rounding process. Journal of Trauma Nursing, 17(2), $69-71$.

Odedra, K., Hitchcock, J. (2012). Implementation of nursing grand rounds at a large acute hospital trust. British Journal of Nursing, 12(3), 182-185.

Ogrinc, G., Mooney, S. E., Estrada, C., Foster, T., Goldman, D., Hall, L. W., Watts, B. (2008). The SQUIRE (Standards for Quality Improvement Reporting Excellence) guidelines for quality improvement reporting: explanation and elaboration. Quality \& Safety in Health Care, 17 (1), 13-32.

Rideout, K. (2007). Evaluation of a PNP care coordinator model for hospitalized children, adolescents, and young adults with cystic fibrosis. Pediatric Nursing, 33(1), 29-36.

Segal, S., \& Mason, D. J. (1998). The art and science of teaching rounds: A strategy for staff development. Journal For Staff Development, 14(3), 127-136.

Shebesta, K., Cook, B., Rickets, C., Schweer, L., Brown, R., Garcia, V., \& Falcone, R. (2006). Pediatric trauma nurse practitioners increase bedside nurses' satisfaction with pediatric trauma patient care. Journal of Trauma Nursing, 13(2), 66-69. 
Stewart, J., Stansfield, K., \& Tapp, D. (2004). Clinical nurses' understanding of autonomy accomplishing patient goals through interdependent practice. Journal of Nursing Administration, 34, 443-450.

Stolee, P., Hillier, L., Esbaugh, J., Griffiths, N., \& Borrie, M. (2006). Examining the nurse practitioner role in long-term care: Evaluation of a pilot project in Canada. Journal of Gerontological Nursing, 32(10), 28-36.

Thompson, C., McCaughan, D., Cullum, N., Sheldon, T. A., Mulhall, A., \& Thompson, D. R. (2001). Research information in nurses' clinical decision-making: What is useful? Journal of Advanced Nursing, 36(3), 376-388.

Tracy, M.F., \& Hanson, C.M. (2013).Leadership In A.B. Hamric, C. M. Hanson, M.F. Tracy, \& E.T. O' Grady (Eds.),Advanced Practice Nursing: An Integrative Approach. (pp. 266-298; $5^{\text {th }}$ ed.). St. Louis, MO: Saunders/Elsevier.

von Elm, E., Altman, D. G., Egger, M., Pocock, S. J., Gotzsche, P. C., Vandenbroucke, J. P., (2007). The strengthening and reporting of observational studies in epidemiology (STROBE) statement: guidelines for reporting observational studies. Annuals of Internal Medicine, 147 (8), 573-577.

Ward, D.J., Furber, C., Tierney, S., Swallow, V. (2013). Using framework analysis in nursing research: a worked example. Journal of Advanced Nursing, 69(11), 242331.

Weston, M. J. (2010). Strategies for enhancing autonomy and control over nursing practice. The Online Journal of Issues in Nursing. Retrieved January 25, 2013, from http://www.nursingworld.org/ 
Williamson, S., Twelvetree, T., Thompson, J., Beaver, K. (2012). An ethnographic study exploring the role of ward-based advanced nurse practitioners in an acute medical setting. Journal of Advanced Nursing, 68(7), 1579-88.

Wolak, E. S., Cairns, B., Smith, E. (2008). Nursing grand rounds as a medium for the continuing education of nurses. The Journal of Continuing Education in Nursing, 39(4), 173-178. 
Table 1

Unit Based Nursing Rounds

\begin{tabular}{|c|c|c|c|c|c|c|}
\hline $\begin{array}{l}\text { Author } \\
\text { (year) }\end{array}$ & $\begin{array}{l}\text { Study } \\
\text { design/method }\end{array}$ & Study focus & Sample/setting & Intervention & Findings/conclusions & Limitations \\
\hline $\begin{array}{l}\text { Cooper } \\
(1982)\end{array}$ & $\begin{array}{l}\text { Description of } \\
\text { nursing rounds }\end{array}$ & Not a study & None & None & None & Not a study \\
\hline $\begin{array}{l}\text { Coleman \& } \\
\text { Henneman } \\
(1991)\end{array}$ & $\begin{array}{l}\text { Pre- and post } \\
\text { intervention } \\
\text { chart audit, post } \\
\text { intervention } \\
\text { observation and } \\
\text { questionnaire }\end{array}$ & $\begin{array}{l}\text { Ensure } \\
\text { comprehensive } \\
\text { patient care } \\
\text { and care } \\
\text { planning } \\
\text { documentation }\end{array}$ & Not identified & $\begin{array}{l}\text { Unit based } \\
\text { nursing } \\
\text { rounds by } \\
\text { APRN and } \\
\text { Clinical } \\
\text { educator, } \\
\text { case study } \\
\text { approach }\end{array}$ & $\begin{array}{l}\text { Pre and post chart audit } \\
\text { improved documentation } \\
\text { in areas of social } \\
\text { interaction and } \\
\text { developmental/normalcy. } \\
\text { Positive response of } \\
\text { nurses to unit based } \\
\text { rounds }\end{array}$ & $\begin{array}{l}\text { Quasi- } \\
\text { experimental. } \\
\text { Unknown } \\
\text { sample size or } \\
\text { setting. } \\
\text { Unknown } \\
\text { number of } \\
\text { respondents } \\
\text { No } \\
\text { assessment of } \\
\text { nurse } \\
\text { satisfaction }\end{array}$ \\
\hline $\begin{array}{l}\text { Segal \& } \\
\text { Mason } \\
(1998)\end{array}$ & $\begin{array}{l}\text { Post } \\
\text { intervention } \\
\text { survey. } \\
\text { Post } \\
\text { intervention } \\
\text { chart review. } \\
\text { Comparative } \\
\text { analysis of the } \\
\text { process. }\end{array}$ & $\begin{array}{l}\text { Staff } \\
\text { development } \\
\text { in pain } \\
\text { management. } \\
\text { Theoretical } \\
\text { Framework: } \\
\text { Brookfield's } \\
\text { process of } \\
\text { critical } \\
\text { reflective } \\
\text { thinking }\end{array}$ & $\begin{array}{l}\text { Medical } \\
\text { surgical units of } \\
\text { a large medical } \\
\text { center in US }\end{array}$ & $\begin{array}{l}\text { Unit based } \\
\text { nursing } \\
\text { rounds led by } \\
\text { an APRN. } \\
\text { Presentation } \\
\text { of patient by } \\
\text { staff nurse, } \\
\text { interview of } \\
\text { patient by } \\
\text { APRN, } \\
\text { discussion by } \\
\text { group. }\end{array}$ & $\begin{array}{l}\text { Surveys results: } 39 \% \\
\text { best teaching method and } \\
61 \% \text { good teaching } \\
\text { method. }\end{array}$ & $\begin{array}{l}\text { No data on } \\
\text { patient } \\
\text { outcomes or } \\
\text { nurse } \\
\text { satisfaction. } \\
\text { No data on } \\
\text { response rate } \\
\text { of surveys. No } \\
\text { data on chart } \\
\text { reviews. } \\
\text { Quasi- } \\
\text { experimental. }\end{array}$ \\
\hline
\end{tabular}




\begin{tabular}{|l|l|l|l|l|l|l|}
\hline $\begin{array}{l}\text { Close and } \\
\text { Castledine } \\
\text { (2005) }\end{array}$ & $\begin{array}{l}\text { Not a study, } \\
\text { description of } \\
\text { nursing rounds } \\
\text { conducted by } \\
\text { nurse managers } \\
\text { to monitor } \\
\text { patient care } \\
\text { activities }\end{array}$ & None & Not identified & $\begin{array}{l}\text { Rounds by } \\
\text { nurse manager } \\
\text { to monitor } \\
\text { patient care } \\
\text { activities and } \\
\text { meet } \\
\text { immediate } \\
\text { patient needs }\end{array}$ & None & Not a study \\
\hline $\begin{array}{l}\text { Castledine, } \\
\text { Grainger \& } \\
\text { Close } \\
\text { (2005) }\end{array}$ & $\begin{array}{l}\text { Not a study, } \\
\text { description of } \\
\text { nursing rounds to } \\
\text { meet the physical } \\
\text { needs of patients }\end{array}$ & None & Not identified & $\begin{array}{l}\text { Rounds to } \\
\text { address } \\
\text { physical needs } \\
\text { of the patient } \\
\text { in a timely } \\
\text { manner. }\end{array}$ & None & Not a study \\
\hline $\begin{array}{l}\text { Mower- } \\
\text { Pade \& } \\
\text { Pirrung }\end{array}$ & $\begin{array}{l}\text { Quality } \\
\text { improvement } \\
\text { project. }\end{array}$ & $\begin{array}{l}\text { Facilitate } \\
\text { timely } \\
\text { discharge, } \\
\text { improve } \\
\text { patient flow } \\
\text { and increase } \\
\text { communication }\end{array}$ & $\begin{array}{l}\text { Inpatient } \\
\text { trauma service } \\
\text { in US hospital }\end{array}$ & $\begin{array}{l}\text { Daily formal } \\
\text { rounding } \\
\text { process with } \\
\text { use of a daily } \\
\text { checklist. }\end{array}$ & $\begin{array}{l}\text { Shortened length of } \\
\text { stay. Improved } \\
\text { patient, nurse and } \\
\text { physician satisfaction. }\end{array}$ & $\begin{array}{l}\text { No data were } \\
\text { presented. }\end{array}$ \\
\end{tabular}




\begin{tabular}{|c|c|c|c|c|c|c|}
\hline $\begin{array}{l}\text { Gardner et } \\
\text { al. (2010) }\end{array}$ & $\begin{array}{l}\text { Pilot study. } \\
\text { One group pre- } \\
\text { post test design } \\
\text { on effectiveness } \\
\text { of the strategy } \\
\text { and nursing } \\
\text { satisfaction. }\end{array}$ & $\begin{array}{l}\text { Assess } \\
\text { innovation in } \\
\text { clinical } \\
\text { learning using } \\
\text { unit based } \\
\text { nursing rounds }\end{array}$ & $\begin{array}{l}\text { Acute surgical } \\
\text { ward in } \\
\text { Queensland, } \\
\text { Australia }\end{array}$ & $\begin{array}{l}\text { Nursing rounds } \\
\text { in classroom } \\
\text { on unit one day } \\
\text { a week. } \\
\text { Presented by } \\
\text { bedside nurse } \\
\text { with assistance } \\
\text { from senior } \\
\text { nurses. Patients } \\
\text { and families } \\
\text { may be } \\
\text { present. No } \\
\text { mention of } \\
\text { APRNs }\end{array}$ & $\begin{array}{l}\text { In study site nursing } \\
\text { rounds effective and } \\
\text { feasible method to } \\
\text { provide professional } \\
\text { development. No } \\
\text { statistical differences in } \\
\text { pre-post scores using } \\
\text { nursing worklife } \\
\text { satisfaction survey } \\
\text { (NWSS) or practice } \\
\text { environment scale } \\
\text { (PES) Areas of } \\
\text { autonomy, professional } \\
\text { status and interaction } \\
\text { revealed increase in } \\
\text { post test. }\end{array}$ & $\begin{array}{l}\text { Limitation to } \\
\text { generalizabilit } \\
\text { y. } \\
\text { Inconclusive } \\
\text { findings. } \\
\text { Short post test } \\
\text { period of } 4 \\
\text { months. }\end{array}$ \\
\hline $\begin{array}{l}\text { Cantugui \& } \\
\text { Slark } \\
(2012)\end{array}$ & $\begin{array}{l}\text { Descriptive } \\
\text { study }\end{array}$ & $\begin{array}{l}\text { To improve } \\
\text { management of } \\
\text { stroke patients }\end{array}$ & $\begin{array}{l}\text { Stroke } \\
\text { patients on } \\
\text { acute care } \\
\text { wards in a UK } \\
\text { hospital }\end{array}$ & $\begin{array}{l}\text { Unit based } \\
\text { rounds by an } \\
\text { APRN, ward } \\
\text { manager and } \\
\text { charge nurse } \\
\text { done weekly }\end{array}$ & $\begin{array}{l}\text { Early identification and } \\
\text { prevention of stroke } \\
\text { complications. } \\
\text { Increased } \\
\text { communication } \\
\text { between nurses and } \\
\text { patients. Empowerment } \\
\text { of nurse's decision } \\
\text { making. }\end{array}$ & $\begin{array}{l}\text { Nursing } \\
\text { satisfaction } \\
\text { not assessed o } \\
\text { their } \\
\text { perceived } \\
\text { value of the } \\
\text { rounds. }\end{array}$ \\
\hline $\begin{array}{l}\text { Mahanes et } \\
\text { al. (2013) }\end{array}$ & $\begin{array}{l}\text { Description of } \\
\text { APRN led } \\
\text { rounds }\end{array}$ & $\begin{array}{l}\text { Improve nurse } \\
\text { sensitive } \\
\text { patient } \\
\text { outcomes }\end{array}$ & $\begin{array}{l}\text { Four inpatient } \\
\text { acute care } \\
\text { units in US } \\
\text { hospital }\end{array}$ & $\begin{array}{l}\text { Individualized } \\
\text { unit rounds to } \\
\text { meet learning } \\
\text { needs of } \\
\text { particular units }\end{array}$ & $\begin{array}{l}\text { Positive trends in } \\
\text { CAUTI, CLABSI, falls } \\
\text { and pressure ulcers. }\end{array}$ & $\begin{array}{l}\text { Nursing } \\
\text { satisfaction } \\
\text { not assessed. }\end{array}$ \\
\hline
\end{tabular}


Table 2

PES and JES project unit ranking in comparison with other units in the hospital

\begin{tabular}{|c|c|c|c|c|c|c|}
\hline $\begin{array}{c}\text { Mean } \\
\text { PES } \\
\text { Score }\end{array}$ & $\begin{array}{l}\text { Collegial } \\
\text { Nurse- } \\
\text { Physician } \\
\text { Relations }\end{array}$ & $\begin{array}{l}\text { Staffing } \\
\text { and } \\
\text { Resource } \\
\text { Adequacy }\end{array}$ & $\begin{array}{l}\text { Nurse Manager } \\
\text { Ability, Leadership, } \\
\text { and Support of } \\
\text { Nurses }\end{array}$ & $\begin{array}{c}\text { Nursing } \\
\text { Foundations } \\
\text { for Quality of } \\
\text { Care }\end{array}$ & $\begin{array}{c}\text { Nursing } \\
\text { Participation in } \\
\text { Hospital Affairs }\end{array}$ & $\begin{array}{c}\text { Job } \\
\text { Enjoy } \\
\text { ment }\end{array}$ \\
\hline $19^{\text {th }}$ & $35^{\text {th }}$ & $28^{\text {th }}$ & $22^{\text {nd }}$ & $12^{\text {th }}$ & $9^{\text {th }}$ & $19^{\text {th }}$ \\
\hline
\end{tabular}




\section{Appendix 1}

Questionnaire for Unit Based Rounds for Nurses

1. What do you like about nursing rounds?

2. What do you dislike about nursing rounds?

3. Do you feel nursing rounds increase your knowledge?

4. Do you want to continue nursing rounds? Why or why not

5. Do you have any suggestions for nursing rounds?

6. Does having nursing rounds affect your job satisfaction? How? 


\section{Appendix 2}

\section{Demographic Questionnaire}

1. What is your current level on the UVA clinical ladder?

2. How many years have you been a nurse?

3. How many years have you been on this unit?

4. What current degrees do you hold?

5. Are you currently enrolled in classes to pursue a higher degree?

6. What degree are you currently seeking?

7. What is your age? 
Appendix 3

\section{Practice Environment Scale}

Stem: For each item, please indicate the extent to which you agree that the item is PRESENT IN YOUR CURRENT JOB.

Response options: strongly agree, agree, disagree, strongly disagree.

1. Nurse Participation in Hospital Affairs

Definition: the participatory role and valued status of nurses in a broad hospital context

a. Career development/clinical ladder opportunity.

b. Opportunity for staff nurses to participate in policy decisions

c. A chief nursing officer who is highly visible and accessible to staff.

d. A chief nursing officer equal in power and authority to other top-level hospital executives.

e. Opportunities for advancement.

f. Administration that listens and responds to employee concerns.

g. Staff nurses are involved in the internal governance of the hospital (e.g., practice and policy committees).

h. Staff nurses have the opportunity to serve on hospital and nursing committees.

i. Nursing administrators consult with staff on daily problems and procedures.

Response options: strongly agree, agree, disagree, strongly disagree.

2. Nursing Foundations for Quality of Care

Definition: a pervasive nursing philosophy, a nursing (rather than a medical) model of care, and nurses' clinical competence and development.

a. Active staff development or continuing education programs for nurses.

b. High standards of nursing care are expected by the administration.

c. A clear philosophy of nursing that pervades the patient care environment.

d. Working with nurses who are clinically competent.

e. An active quality assurance program.

f. A preceptor program for newly hired RNs.

g. Nursing care is based on a nursing, rather than a medical, model.

h. Written, up-to-date nursing care plans for all patients.

i. Patient care assignments that foster continuity of care, i.e., the same nurse cares for the patient from one day to the next.

Response options: strongly agree, agree, disagree, strongly disagree.

3. Nurse Manager Ability, Leadership, and Support of Nurses

Definition: the critical role and key qualities of the nurse manager and ways the nurse manager supports the nurse.

a. A supervisory staff that is supportive of the nurses.

b. Supervisors use mistakes as learning opportunities, not criticism. 
c. A nurse manager who is a good manager and leader.

d. Praise and recognition for a job well done.

e. A nurse manager who backs up the nursing staff in decision-making, even if the conflict is with a physician.

4. Staffing and Resource Adequacy

Definition: having adequate staff and support resources to provide quality patient care

a. Adequate support services allow me to spend time with my patients.

b. Enough time and opportunity to discuss patient care problems with other nurses.

c. Enough registered nurses to provide quality patient care.

d. Enough staff to get the work done.

5. Collegial Nurse-Physician Relations

Definition: the positive work relationships between nurses and physicians

a. Physicians and nurses have good working relationships.

b. A lot of team work between nurses and physicians.

c. Collaboration (joint practice) between nurses and physicians.

\section{Job Enjoyment}

Definition: Measure of the degree to which people like their work.

Stem: Nurses with whom I work would say that they:

a. Are fairly well satisfied with their jobs.

b. Would not consider taking another job.

c. Have to force themselves to come to work much of the time.

d. Are enthusiastic about their work almost every day.

e. Like their jobs better than the average worker does.

f. Feel that each day on their job will never end.

g. Find real enjoyment in their work.

Response options: strongly agree, agree, tend to agree, tend to disagree, disagree, strongly disagree 
Appendix 4

Author Guidelines for Submission to the Journal of Advanced Nursing

Last updated: November 2013

Every paper submitted should be structured and written in accordance with JAN requirements and guidelines. This is to ensure completeness of content and clear structure. Papers that do not comply with $J A N$ 's essential requirements will be immediately returned.

\section{International Relevance}

Papers submitted should be relevant to the Aims \& Scope of JAN and written in a way that makes the relevance of content clear for $J A N$ 's international readership. Points to consider are: whether a reader in a region or country very different from your own will be able to make sense of everything in your paper

- whether you have clearly outlined the relevance of your paper to the subject field internationally and also its transferability into other care settings, cultures or nursing specialities

- if your paper explores focussed cultural or other specific issues, have you clearly placed the discussions within an international context?

\section{English language}

A high standard of written English language is important for easy understanding internationally. Authors who are not fluent English language writers are strongly recommended to ensure that their manuscript is copy-edited by a native English speaker prior to submission. Visit our site to learn about the options. Please note that using the Wiley English Language Editing Service does not guarantee that your paper will be accepted by this journal.

\section{Currency of data}

The period of data collection should be specified in an empirical research report, both in the abstract and in the body of the paper, in the form of a statement such as 'the data were collected during 2008' or 'data were collected over a 18 months in 2006-2007'. Timely publication of results is regarded as good research practice: therefore, if the data are more than five years old by the time you are ready to submit your paper, or in the case of new analysis of older data sets, the contemporary relevance of the data should be clearly (and explicitly) explained in the text of the paper and commented on briefly in the abstract. A review paper should include, both in the text and the abstract, the inclusive dates of the literature searched and normally the search should have been completed no longer than three years before you submit the paper. Papers in the form of a protocol should mention in the text and the abstract the date (month and year) of its ethical approval and/or funding, and must be submitted in sufficient time to allow publication before the study is reported. 


\section{Length}

Papers must not exceed 5000 words. The word count includes quotations, but excludes the abstract, keywords, summary statement, references, figures and tables. There is a facility that allows lengthy or supplementary material to be published online in addition to the paper. Papers shorter than 5000 words are welcome. In exceptional circumstances and only for high quality reviews, authors can request to exceed the 5000 word limit.

\section{More than one paper}

If more than one paper from the same study is being prepared for $J A N$ they should be submitted as separate papers. When more than one paper is prepared from the same study there should be minimal duplication and no 'cut and paste' of material across the papers. It might be appropriate, for example, to describe the research methods fully in one paper and give a summary of these in a second paper, with reference to the fuller description in the first paper. However done, there must always be direct referencing to any other paper/s from the same study that has/have been published (or 'in press'). We may ask you to provide copies of other such papers to check overlap. Note that the rules that apply to plagiarism are equally applicable to one's own work. Authors also should be aware that $J A N$ does not support the practice of publishing small sections of a study in several separate papers when a well-crafted single paper would suffice. If more than one paper is produced from the same study, each must address, in-depth, different aspects of the study, or reporting that study in distinctly different ways for different readerships; 'salami slicing' is discouraged. Mixed methods studies that are reported in one paper may be particularly rich and meaningful when triangulation of qualitative and quantitative data is evident and findings from both types of data amplify and clarify the study topic.

\section{Supplementary web-based information}

Note that Supplementary Information can be put online alongside a published paper: for example, in the form of additional tables or other types of data or further details about methods and measures.

\section{Search Engine Optimisation}

Many students and researchers looking for information online will use search engines such as Google, Yahoo or similar. By optimising your article for search engines, you will increase the chance of someone finding it. This in turn will make it more likely to be viewed and/or cited in another work. We have compiled these guidelines to enable you to maximize the web-friendliness of the most public part of your article.

In addition, please see the Tips Sheet for optimising the discoverability of your article and promoting it post-publication.

Please also see this Wiley Exchanges blog post for advice on choosing keywords for your article.

\section{Title Page}

Your title page should include the following information:

- Full title (maximum 25 words) 
- Running head

- Author details: names (please put last names in CAPITALS), job titles and affiliations (maximum of 3 per author), qualifications (maximum of 3 per author, including RN/RM where appropriate)

- Acknowledgements (if applicable)

- Conflict of Interest statement

- Funding Statement

\section{Authorship}

All authors must have agreed on the final version of the paper and must meet at least one of the following criteria (based on those recommended by the ICMJE):

1) substantial contributions to conception and design, acquisition of data, or analysis and interpretation of data

2) drafting the article or revising it critically for important intellectual content.

\section{Structure and format}

To ensure completeness of content there is a recommended structure and format for different types of papers. We also ask that you include all information required by the reporting guidelines relevant to your study. Please consult the EQUATOR Network for details.

Please click below on the type of paper you are planning to submit, and follow the guidance provided.

JAN also welcomes other types of paper that do not fit into the above categories. Please contact the editorial office in the first instance (jan@ wiley.com).

\section{Evidence Synthesis:}

Systematic review or other type of review

Concept analysis

Guidelines and consensus statements

Discussion Paper

\section{Research Papers:}

Original Research:

Empirical research - quantitative

Empirical research - qualitative

Empirical research - mixed methods

$\underline{\text { Clinical trial }}$

Pilot Study

Protocols:

Protocols for a research study or systematic review

Research Methodology:

$\underline{\text { Instrument Development }}$ 
Discussion Paper - Methodology

Empirical Research - Methodology

JAN Forum Contribution:

$\underline{J A N}$ Forum Contribution

\section{Case Reports}

$J A N$ does not accept case reports for publication. Authors of case reports are encouraged to submit to the Wiley Open Access journal, Clinical Case Reports, which aims to directly improve health outcomes by identifying and disseminating examples of best clinical practice.

\section{References}

References follow the Harvard style, i.e. parenthetical in the text and listed in alphabetical order of first authors' names in the reference list.

The editor and publisher recommend that citation of online published papers and other material should be done via a DOI (digital object identifier), which all reputable online published material should have - see www.doi.org for more information. If an author cites anything which does not have a DOI they run the risk of the cited material not being traceable.

We recommend the use of a tool such as EndNote or Reference Manager for reference management and formatting.

References within the text should cite the authors' names followed by the date of publication, in chronological date order, e.g. (Lewis 1975, Barnett 1992, Chalmers 1994). Where there are more than two authors, the first author's name followed by 'et al.' will suffice, e.g. (Barder et al. 1994), but all authors should be cited in the reference list. 'et al.' should be presented in italics followed by a full stop only. Page numbers should be given in the text for all quotations, e.g. (Chalmers 1994, p. 7). All references should be cited from primary sources.

Where more than one reference is being cited in the same pair of brackets the reference should be separated by a comma; authors and dates should not be separated by a comma, thus (Smith 1970, Jones 1980). Where there are two authors being cited in brackets - but not in the main text - then they should be joined by an ' $\&$ ', thus (Smith \& Jones 1975).

When a paper is cited, the reference list should include authors' surnames and initials, date of publication, title of paper, name of journal in full (not abbreviated), volume number, and first and last page numbers. Example: Watson R, Hoogbruin AL, Rumeu C, Beunza M, Barbarin B, MacDonald J \& McReady T (2003) Differences and similarities in the perception of caring between Spanish and United Kingdom nurses. Journal of Clinical Nursing 12, 85-92. 
When a book is cited, the title should be stated, followed by the publisher and town/county/state (and country if necessary) of publication. Example: Smith GD \& Watson R (2004) Gastroenterology for Nurses. Blackwell Science, Oxford.

Where the reference relates to a chapter in an edited book, details of author and editors should be given as well as publisher, place of publication, and first and last page numbers. Example: Chalmers KI (1994) Searching for health needs: the work of health visiting. In Research and its Application (Smith JP ed.), Blackwell Science, Oxford, pp. 143-165.

The edition (where appropriate) of all books should be identified, e.g. 2nd edn.

References stated as being 'in press' must have been accepted for publication and a letter of proof from the relevant journal must accompany the final accepted manuscript. Please provide access details for online references where possible: Example: Lynaugh JE (1997) The International Council of Nurses is Almost 100 years old. University of Pennsylvania, PA. Available at: http://www.nursing.upenn.edu/history/Chronicle/F97/icn.htm (accessed 12 December 2002). The reference list should be prepared on a separate sheet and be in alphabetical order and chronological order by first authors' surnames.

We encourage you to refer to existing literature published in $J A N$ where relevant.

\section{Figures and tables}

Include a citation in the text for each figure and table. Artwork should be submitted online in electronic form. Detailed information on our digital illustration standards is available from:

http://authorservices.wiley.com.proxy.its.virginia.edu/bauthor/journal.asp.

Abbreviations used in figures and tables should be defined in a footnote.

Approval for reproduction/modification of any material (including figures and tables) published elsewhere should be obtained by the authors/copyright holders before submission of the manuscript. Contributors are responsible for any copyright fee involved.

\section{Preparation of electronic figures for publication:}

Although low quality images are adequate for review purposes, print publication requires high quality images to prevent the final product being blurred or fuzzy. Submit EPS (line art) or TIFF (halftone/photographs) files only. MS PowerPoint and Word Graphics are unsuitable for printed pictures. Do not use pixel-oriented programmes. Scans (TIFF only) should have a resolution of at least 300 dpi (halftone) or 600 to 1200 dpi (line drawings) in relation to the reproduction size (see below). Please submit the data for figures in black and white or submit a Colour Work Agreement Form (see Colour Charges below). EPS files should be saved with fonts embedded (and with a TIFF preview if possible). 
For scanned images, the scanning resolution (at final image size) should be as follows to ensure good reproduction: line art: >600 dpi; halftones (including gel photographs): >300 dpi; figures containing both halftone and line images: $>600 \mathrm{dpi}$.

Always include a citation in the text for each figure and table. Artwork should be submitted online in electronic form. Detailed information on our digital illustration standards is available on the Wiley-Blackwell website.

Permissions: If all or parts of previously published illustrations are used, permission must be obtained from the copyright holder concerned. It is the author's responsibility to obtain these in writing and provide copies to the Publisher.

Colour charges: It is the policy of JAN for authors to pay the full cost for the reproduction of their colour artwork. Therefore, please note that if there is colour artwork in your manuscript when it is accepted for publication, Wiley-Blackwell require you to complete and return a Colour Work Agreement Form before your paper can be published. Any article received by Wiley-Blackwell with colour work will not be published until the form has been returned. Please return all original hard-copy forms to:

The Production Editor

Journal of Advanced Nursing

Journal Content Management

Wiley Services Singapore Pte Ltd

1 Fusionopolis Walk

\#07-01 Solaris South Tower

Singapore 138628

\section{Statistical guidelines}

Details on how to present statistical information in your paper can be found here.

\section{Publication ethics}

For more information visit:

http://authorservices.wiley.com.proxy.its.virginia.edu/bauthor/publicationethics.asp If

you have any questions that are not answered by the information provided on this

website, please email the Editorial Office at jan@ wiley.com.

\section{Conflict of interest}

Authors are required to disclose any possible conflict of interest when submitting a paper. These can include financial conflicts of interest e.g. patent ownership, stock ownership, consultancies, speaker's fee. All conflict of interest (or information specifying the absence of conflict of interest) should be included at the end of the article under 'Conflicts of Interest'. This information will be included in the published article.

If the author does not have any conflict of interest the following statement should be included: 'No conflict of interest has been declared by the author(s).' 
Editors of $J A N$ are encouraged to publish in $J A N$. To avoid conflicts of interest, editors do not process their own papers. If a member of the editorial team is submitting to JAN, then the ScholarOne system prevents them from viewing any details related to their paper and also prevents the manuscript from being allocated to them for review, regardless of their place in the authorship of the paper. If the Editor-in-Chief is submitting a paper then the Editorial Assistant is informed and the paper allocated to one of the editors for processing. Editors are also urged to be aware of other potential conflicts of interest such as processing papers by collaborators and colleagues. Such situations are unavoidable but editors are expected to exercise discretion and fairness regardless of any proximity to submitting authors.

\section{Funding}

$J A N$ requires authors to specify any sources of funding (institutional, private and corporate financial support) for the work reported in their paper. This information, in the form of the name of the funding organisation/s and the grant number should be included at the end of the article under the heading 'Funding', and provided at the time of submitting the paper. If there was no funding, the following wording should be used: 'This research received no specific grant from any funding agency in the public, commercial, or not-for-profit sectors.' Any suppliers of materials should be named and their location (town, state/county, country) included if appropriate. This information will be included in the published article.

\section{Summary Statements}

All manuscripts must include a Summary Statement. Please refer to the Summary Statement guidelines. 
Appendix 5

IRB Approval 
